\title{
Could protein content of Urinary Extracellular Vesicles be useful to detect Alcoholic Liver Disease and assess Hepatocarcinoma risk?
}

Gonzalez E. ${ }^{1, *}$, Azkargorta M. ${ }^{2}$, Garcia-Vallicrosa C. ${ }^{1}$, Prieto-Elordui J. ${ }^{3}$, Elortza F. ${ }^{2}$, BlancoSampascual S. ${ }^{3}$, Falcon-Perez JM ${ }^{1,4,5, *}$

1 Exosomes Laboratory. Center for Cooperative Research in Biosciences (CIC bioGUNE), Basque Research and Technology Alliance (BRTA), Derio, Spain; egonzalez@cicbiogune.es; cgarcia@cicbiogune.es; jfalcon@cicbiogune.es

2 Proteomics Platform. Center for Cooperative Research in Biosciences (CIC bioGUNE), Basque Research and Technology Alliance (BRTA), Derio, Spain; mazkargorta@cicbiogune.es; felortza@cicbiogune.es

3 Servicio de Aparato Digestivo, Hospital Universitario de Basurto, Bilbao, Vizcaya, España; janire.prietoelordui@osakidetza.eus; sonia.blancosampascual@osakidetza.eus

4 Centro de Investigación Biomédica en Red de enfermedades hepáticas y digestivas (CIBERehd) Madrid Spain

5 IKERBASQUE Basque Foundation for Science Bilbao Spain.

6 * Correspondence: egonzalez@cicbiogune.es; jfalcon@cicbiogune.es ; Tel.: +34 946572508 (E.G.); +34 944061319 (J.M.F.)

\section{Simple Summary:}

Alcohol abuse can lead to alcoholic liver disease (ALD), that causes high mortality and morbidity, resulting in a great burden on world health. ALD is not usually evidenced until symptoms appear once disease is advanced, being indeed difficult to predict and detect the progression of the disease to fibrosis, cirrhosis and finally hepatocarcinoma, as well as the underlying etiology. Non-invasive methodologies are convenient for avoiding suffering and complications to patients, especially the most weakened. With this in mind, we studied if urinary EVs (uEVs) associated proteins could be useful for diagnosing and evaluating ALD. By analyzing urine samples of a cohort of cirrhotic and non-cirrhotic patients, we were able to detect changes in uEVs concentration, size and protein composition, contributing to appraise uEVs as a valuable tool in ALD. Furthermore, our work highlights the technical limitations to be taken into consideration in the future, stablishing in this way a baseline of knowledge for further research in the field.

\section{Abstract:}

(1) Background: Alcohol abuse has a high impact on the mortality and morbidity related to a great number of diseases and is responsible for the development of alcoholic liver disease (ALD). It remains challenging to detect and evaluate its severity, which is crucial for prognosis. In this work, we studied if urinary EVs (uEVs) could serve in diagnose and evaluate cirrhosis in ALD.

(2) Methods: uEVs characterization by cryo-electron microscopy (Cryo-EM), Nanoparticle Tracking Analysis (NTA) and Western blotting (WB) was performed in a cohort of 21 controls and 21 cirrhotic patients. Then, proteomics of urinary EVs (uEVs) was carried out in a second cohort of 6 controls and 8 patients in order to identify new putative biomarkers for cirrhosis in ALD.

(3) Results: uEVs concentration, size and composition were altered in cirrhotic patients. A total of 1304 proteins were identified in uEVs, and 90 of them were found to be altered in cirrhotic patients. 
(4) Conclusions: uEVs could be considered as a tool and a supplier of new biomarkers for ALD, whose application would be especially relevant in chronic patients. Yet, further research is necessary to obtain more relevant result in clinical terms.

Keywords: extracellular vesicles (EVs); urinary extracellular vesicles (uEVs); exosomes; biomarkers; liquid biopsy; cirrhosis; fibrosis; hepatocarcinoma (HCC); alcoholic liver disease (ALD).

\section{Graphical Abstract}

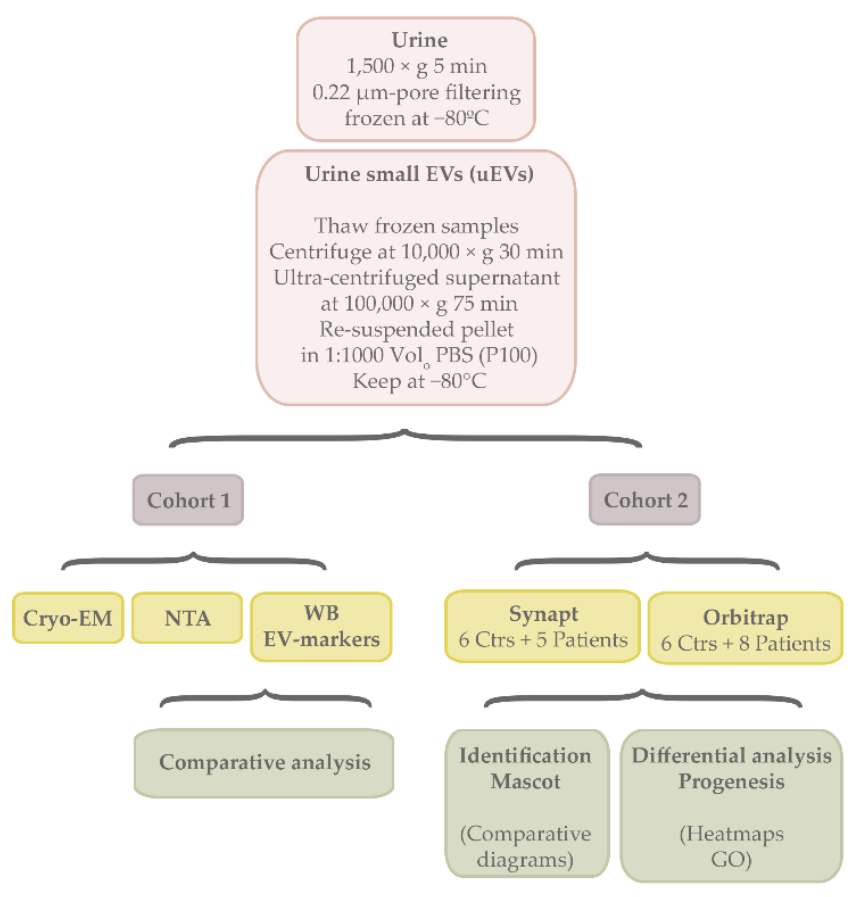

Graphical Abstract. Experimental design workflow from uEVs isolation to management of the cohorts and experimentation and research steps. This work was conducted on two independent cohorts containing non-cirrhotic (controls) and cirrhotic individuals. Small urinary EVs (uEVs) from the Cohort 1 were characterized by cryo-electron microscopy (Cryo-EM), nanoparticle tracking analysis (NTA) and Western blotting (WB) for EV markers. Small uEVs from Cohort 2 were subjected to proteome analysis by using two acquisitions strategies (Synapt and Orbitrap spectrophotometers) and Mascot identification. After data gathering, comparative and differential analysis between noncirrhotic and cirrhotic individuals was performed by using statistic tools and specific software.

\section{Introduction}

Alcohol is a psychoactive and toxic substance whose harmful use causes dependence, becoming one of the leading risk factors for population health Worldwide. The impact of alcohol abuse is so relevant, that its prevention and treatment is included specifically by $\mathrm{WHO}$ as a target in the Sustainable Development Goals 3 (SDG 3), together with narcotic drugs. According to WHO, alcohol consumption contributes to 3 million deaths each year globally as well as to disabilities and poor health of millions of people. Overall, harmful use of alcohol is responsible for $5.1 \%$ of the global burden of disease [1]. Indeed, alcohol abuse has an important influence on the mortality and morbidity related to more than 200 diseases and conditions [2,3]. Consequently, the costs associated with alcohol amount to more than $1 \%$ of the gross national product in high and middle-income countries [1]. 
Alcohol is one of the most common causes of digestive diseases and, in particular, of alcoholic liver disease or ALD [3], due to ethanol metabolism-associated products that cause hepatocellular damage [4]. ALD ranges from steatosis and steatohepatitis through progressive fibrosis to cirrhosis and finally, hepatocellular cancer $[5,6]$. More than $90 \%$ of all heavy drinkers develop fatty liver, over $10-35 \%$ of them develop severe alcoholic hepatitis and $8-20 \%$ progress in cirrhosis, while $2 \%$ of which will develop hepatocarcinoma [7]. Steatosis or fatty liver disease is transient and reversible, but acute alcoholic hepatitis and liver cirrhosis are associated with high mortality (up to $50 \%$ in acute alcoholic hepatitis) [8], being the average survival time of patients with advanced liver cirrhosis between 1-2 years [9]. In addition to this, over 80,000 deaths per year are attributable to alcohol-related hepatocellular carcinoma $[10,11]$.

ALD is not usually detected until symptoms appear due to advanced disease development [12]. The current diagnosis of ALD is subjected to the combination of several parameters. Firstly, screening question-based tests assess alcohol abuse and dependence [13] and biochemical parameters that include direct alcohol detection and cellular damage by alcohol intake give rise to an initial diagnostic assessment [13,14]. Additionally, different predictive scores combining many biochemical parameters help obtain a more precise evaluation [14-17]. Nevertheless, none of these parameters are fully efficient in diagnosis and prognosis and all of them lack of specificity and capability of truthfully discriminate ALD from other causes of liver disease, such as obesity, viral hepatitis, and exposure to other toxics [6]. Hence, it is necessary to develop strategies for early and specific diagnosis of ALD according its aetiologic.

Accurate assessment of the full spectrum of ALD is challenging, particularly given the difficulty with discriminating between bland steatosis and steatohepatitis, and fibrosis severity. Liver biopsy remains the only test for precise appraisal, although it proves to be an invasive procedure that carries substantial risk and can cause complications $[6,18]$. Nowadays, non-invasive imaging techniques such as transient elastography (TE, FibroScan ${ }^{\circledR}$ ) [19], alternative sampling [20] and liquid biopsy [12] approaches are being applied in order to improve ALD diagnosis. Research on new early and specific biomarkers resulting from alcohol metabolism is also a strategy that is being followed [13,17]. In ALD, much research is done by the use of blood (serum or plasma) [14]. However, the use of urine offers an interesting new approach, given that it is the least invasive fluid to test, what is especially relevant in chronic or decompensated patients from whom it is often difficult to draw blood. To such extent, urinary extracellular vesicles (uEVs) could be an excellent source to look for new biomarkers [21].

EVs are round-shape vesicles that consist of a lipid bilayer containing cargo such as lipids, RNA, DNA, proteins and metabolites provided by the parental cell, indicating their origin and state [22]. As EVs are secreted by all cell studied so far and can reach not only the cell environment but also different body fluids, they are being studied as sources of new biomarkers in a wide range of diseases $[23,24]$. Liver diseases are not the exception, the involvement of EVs in physiological and pathogenic processes hold by the liver have been extensively demonstrated $[25,26]$ and consequently, their study as biomarkers sources for diagnosis and monitoring of hepatic conditions is granted [27-29].

In this work, we have explored if uEVs associated proteins could detect alcoholic cirrhosis. For this purpose, uEVS concentration, size and EV-associated proteins have been studied, finding several alterations in patients. Remarkably, proteomics and differential analysis found alterations in patients respect to non-cirrhotic individuals in 90 proteins, which could help and complement current ALD diagnosis.

\section{Results}

\subsection{Characterization of small urine EVs from cirrhotic patients and control individuals}

In this study, uEVs obtained from 2 independent cohorts were used (Table 1, Table S1). Both of them included patients diagnosed with alcoholic cirrhosis, male and female genders and an age range comprising individuals between $18-83$ or $27-73$ years old, respectively.

Table 1. Clinical samples. Cohorts 1 and 2 description according to cirrhosis stages, gender and age. 


\begin{tabular}{|c|c|c|c|c|c|c|c|c|c|}
\hline Cohort 1 & $\begin{array}{c}\text { No. } \\
\text { individuals }\end{array}$ & $\begin{array}{c}\text { Male } \\
\text { individuals }\end{array}$ & $\begin{array}{c}\text { Female } \\
\text { individuals }\end{array}$ & $\begin{array}{l}\mathrm{HCC}^{1} \\
\text { (males) }\end{array}$ & $\begin{array}{l}\text { MELD } \\
\text { score }\end{array}$ & $\begin{array}{c}\text { Age } \\
\text { (years) }^{2}\end{array}$ & Age [18-49] & Age $[50-69]^{3}$ & Age $[70-83]^{3}$ \\
\hline $\begin{array}{c}\text { Non-cirrhotic } \\
\text { (Controls) }\end{array}$ & 21 & 14 & 7 & 0 & $6-12$ & $18-81$ & 7 & 5 & 9 \\
\hline Patients $\mathrm{A}^{4}$ & 10 & 6 & 4 & 1 & $8-18$ & $52-83$ & 0 & 4 & 6 \\
\hline Patients B ${ }^{4}$ & 8 & 7 & 1 & 1 & $14-27$ & $50-69$ & 0 & 9 & 0 \\
\hline Patients $\mathrm{C}^{4}$ & 3 & 1 & 2 & 0 & $11-24$ & $37-58$ & 2 & 0 & 0 \\
\hline Cohort 2 & $\begin{array}{c}\text { No. } \\
\text { individuals }\end{array}$ & $\begin{array}{c}\text { Male } \\
\text { individuals }\end{array}$ & $\begin{array}{c}\text { Female } \\
\text { individuals }\end{array}$ & $\begin{array}{l}\text { HCC }^{1} \\
\text { (males) }\end{array}$ & $\begin{array}{l}\text { MELD } \\
\text { score }\end{array}$ & $\begin{array}{c}\text { Age } \\
\text { (years) }^{2}\end{array}$ & Age $[18-49]^{3}$ & Age $[50-69]^{3}$ & Age $[70-83]^{3}$ \\
\hline $\begin{array}{c}\text { Non-cirrhotic } \\
\text { (Controls) }\end{array}$ & 6 & 1 & 5 & 0 & $6-7$ & $27-43$ & 6 & 1 & 0 \\
\hline Patients $\mathrm{A}^{4}$ & 4 & 3 & 1 & 0 & $6-10$ & $58-73$ & 0 & 3 & 1 \\
\hline Patients $\mathrm{B}^{4}$ & 3 & 2 & 1 & 1 & $8-24$ & $43-48$ & 2 & 1 & 0 \\
\hline Patients $\mathrm{C}^{4}$ & 1 & 0 & 1 & 0 & 19 & 46 & 1 & 0 & 0 \\
\hline
\end{tabular}

${ }^{1}$ HCC cases were only in male individuals. ${ }^{2}$ Ranges of age (years). ${ }^{3}$ Number of individuals in the corresponding range of age. Cirrhosis stages according to ${ }^{4}$ Child-Pugh categories (A, B or C).

Small uEVs in the cohort 1 were characterized by cryo-electron microscopy (Cryo-EM), studied their profile population by nanoparticle tracking analysis (NTA) and biochemically analyzed by Western blotting (WB) for EV markers (Figure 1). Cryo-EM showed typical rounded vesicles in a range of 30-200 $\mathrm{nm}$ in size in both controls and patients. Characteristic bilayered, smooth or decorated uEVs with different electron densities were observed supporting the heterogeneity found among the EVs (Figure 1A, B). NTA confirmed these data, showing a certain profile corresponding to small EVs (Figure 1A, B). Immunoblotting analysis detected 4 out 13 proteins well-known to be associated to uEVs: TSG101, Flotillin-1, CD10 and Syntenin-1 (Figure 1C). No signal was obtained for CD63, CD81, Rab27, Caveolin-1, AQP1, AQP2, Glypican-1, Syndecan-4 and EpCAM. 
A

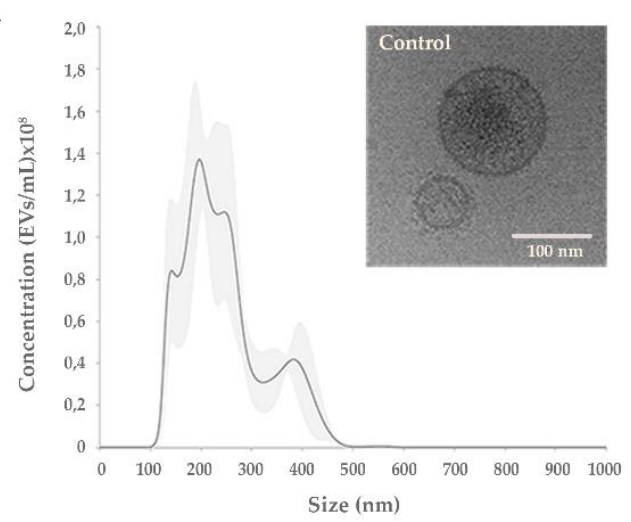

B

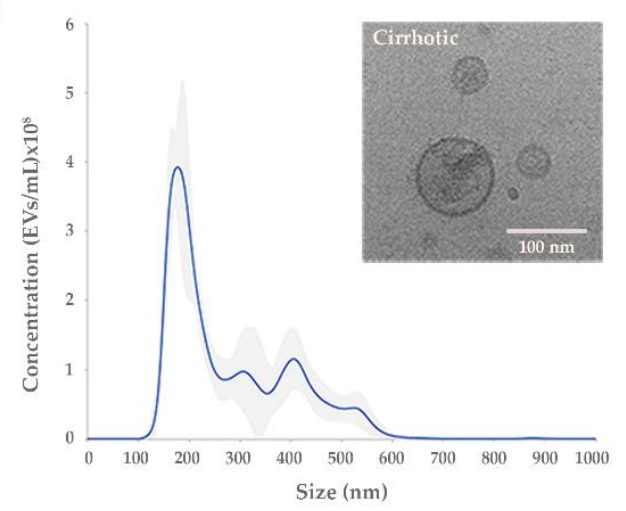

C

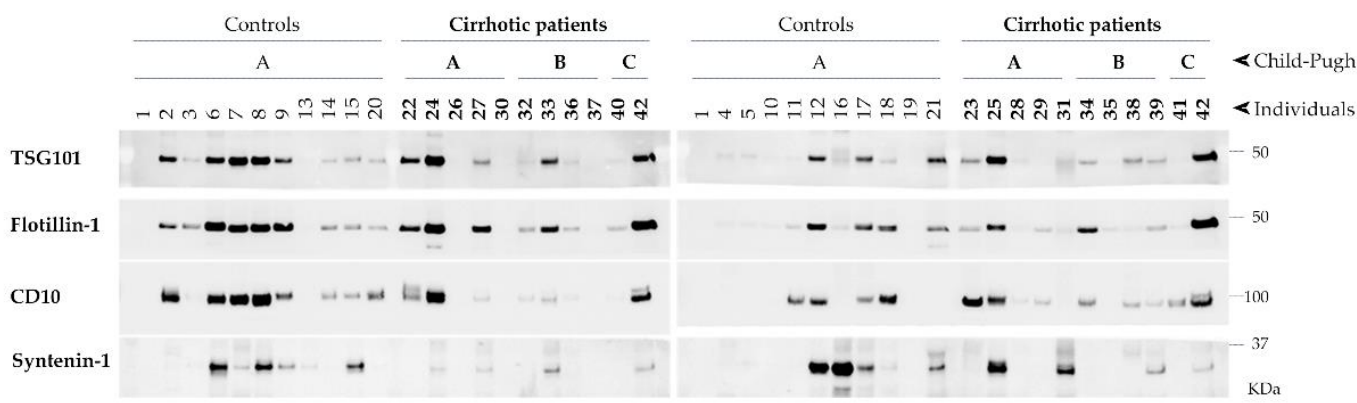

Figure 1. Characterization of uEVs in the cohort 1. A, B) Representative NTA profiles and Cryo-EM images corresponding to a representative non-cirrhotic (Control) individual and a cirrhotic patient. NTA profiles show the average values of 5 measurements and the associated standard deviation for each size in grey shadow. Cryo-EM images show illustrative uEVs. Scale bar $100 \mathrm{~nm}$. C) WB for TSG101, Flotillin1, CD10 and Syntenin-1 on $15 \mu \mathrm{L}$ of sample from 1:1000Volo.

Next, uEVs features were analyzed in detail to know if they could be valuable to diagnose, predict and monitor alcoholic cirrhosis. EV-concentration was observed to slightly increase in cirrhotic patients with respect to controls ( $p>0.05$, Figure 2AA) due mainly to A and C Child-Pugh categories $(p>0.05$, Figure $2 \mathrm{AB}$ ) and especially to the female individuals $<50$ years old that comprise the latest category ( $p>0.05$, Figure 2AC, AD). However, in populations aged between 50-69 differences are also observed ( $p>0.05$, Figure $2 \mathrm{AC}$ ). On the other hand, the most representative EV size (size mode average) also increases in cirrhotic patients due mainly to the EV size that best represent A and B Child-Pugh categories and specially the male population $>70$ years old ( $p>0.05$, Figure 2B). 

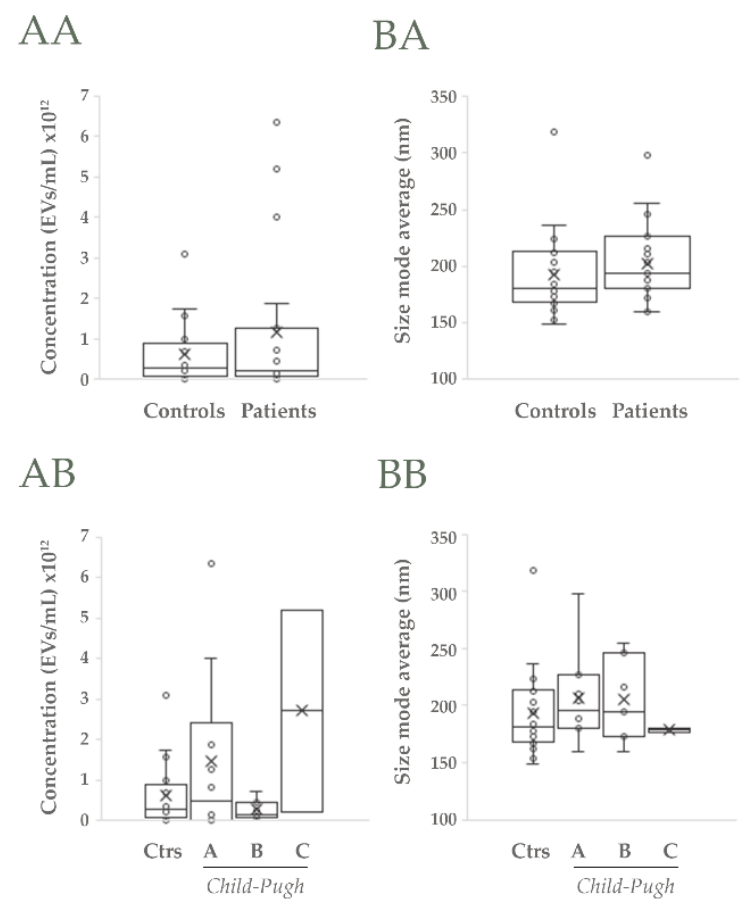

\section{BB}
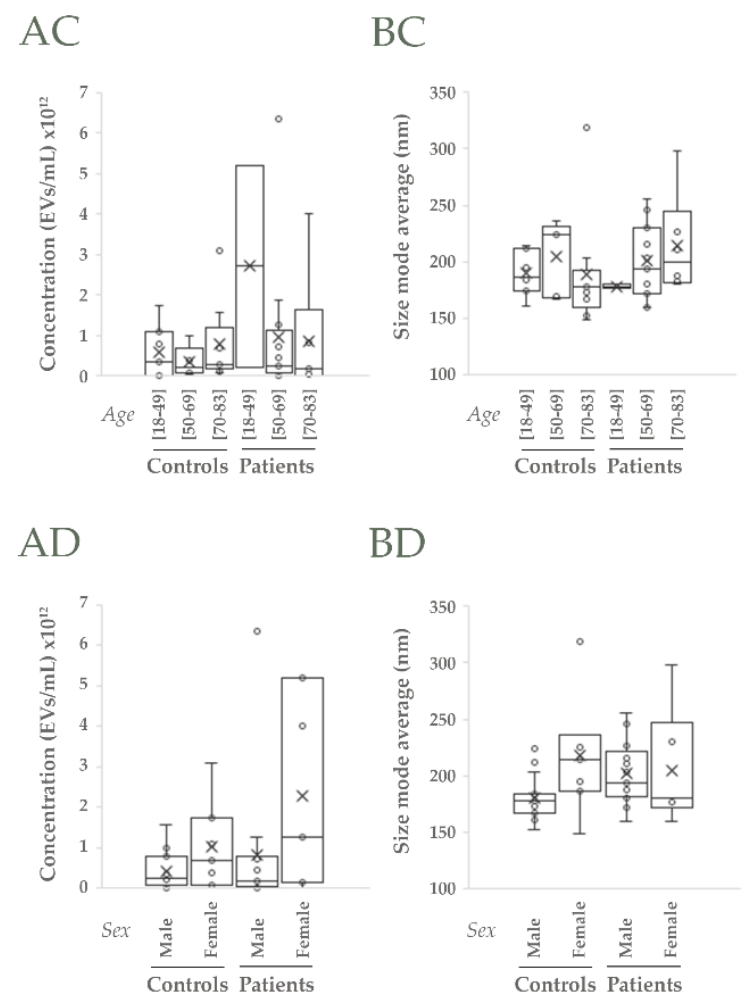

Figure 2. NTA analysis of uEVs in the cohort 1. A, B) Analysis of uEVs in terms of concentration and size (mode), respectively: AA, BA) Non-cirrhotic (Controls) vs cirrhotic patients (t-Student, $p>0.05$ ); $\mathrm{AB}, \mathrm{BB})$ Comparison among Controls, A, B and C Child-Pugh categories; AC, BC) Comparison among three age ranges from both Controls and patients; $\mathrm{AD}, \mathrm{BD})$ Comparison among male and female groups from both Controls and patients (ANOVA, $p>0.05$ in all cases).

TSG101 and Flotillin-1 did not apparently change when compared controls $v$ s patients $(p>0.05$, Figure 3AA, BA), though they increased in cirrhotic patients $>50$ and $>70$ years old respectively $(p>0.05$, Figure 3AC, BC). CD10 and Syntenin- 1 tendered to decrease in cirrhotic people, CD10 mainly in male individuals ( $p>0.05$, Figure 3CD) and Syntenin-1 regardless of gender ( $p>0.05$, Figure 3DD). 
These results suggest that both gender and age contribute to the structure of uEVs populations and their composition. Interestingly, EV concentration and size behave differently in response to these variables.

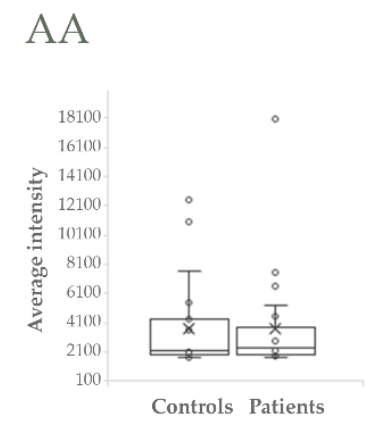

$\mathrm{AB}$

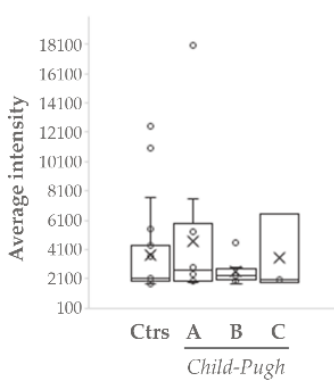

AC

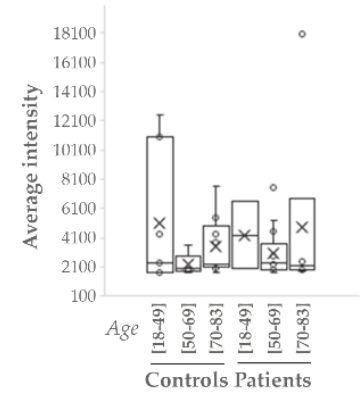

AD

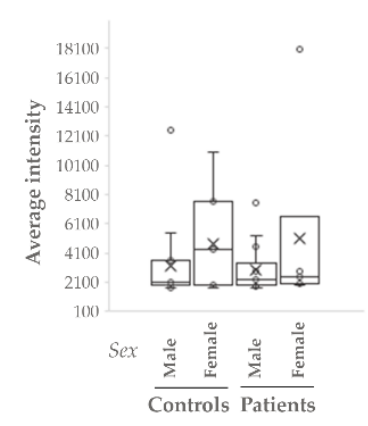

BA

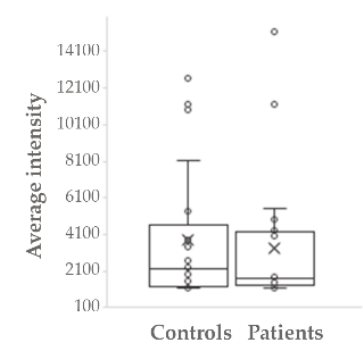

BB

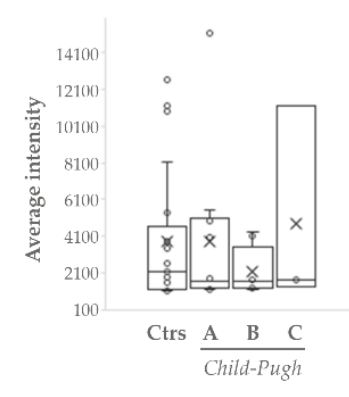

BC

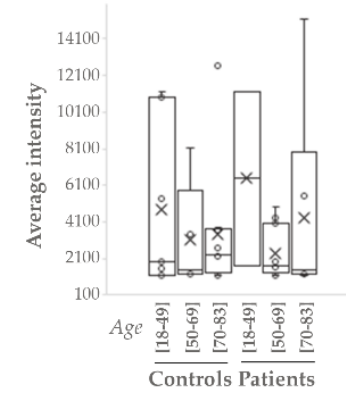

BD

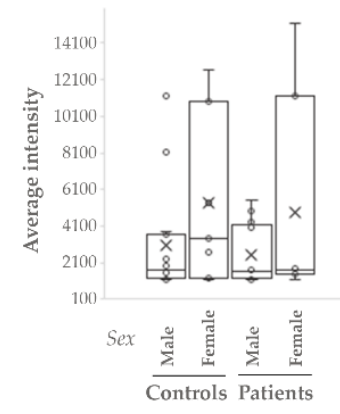

CA

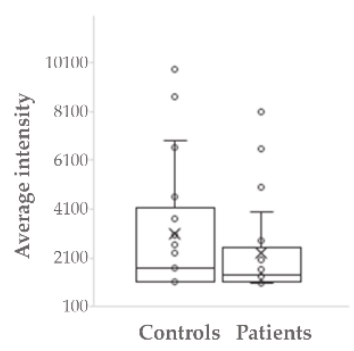

CB

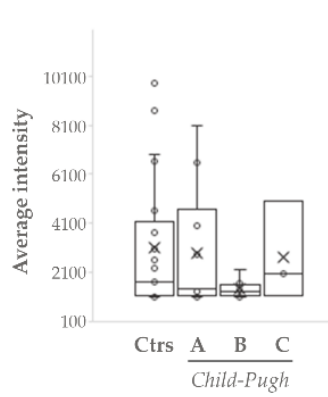

CC

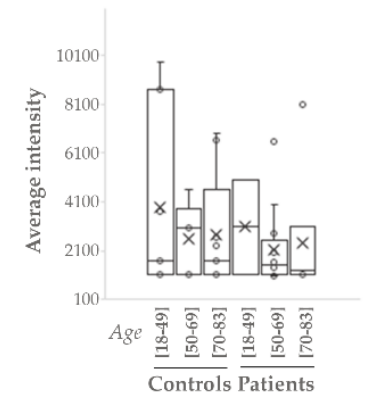

CD

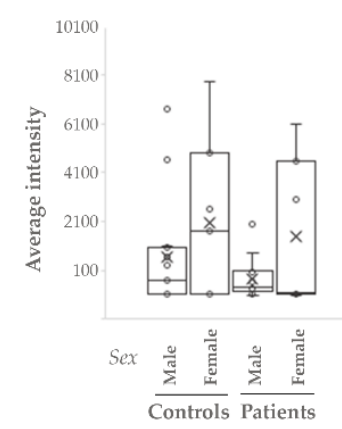

DA

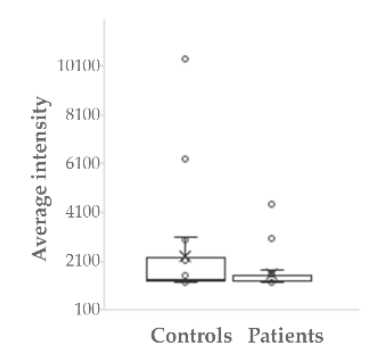

DB

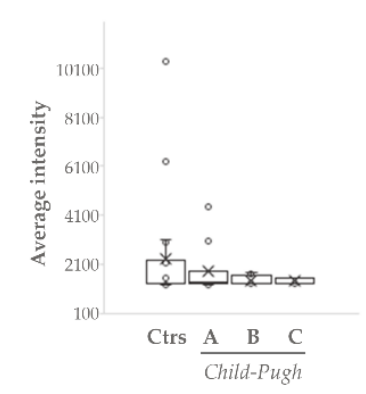

DC

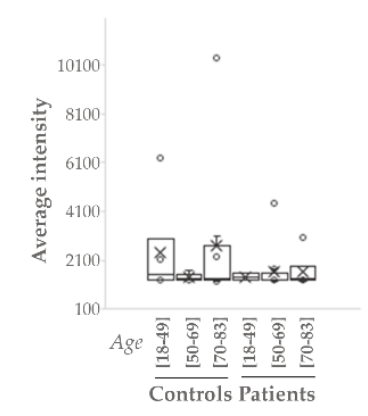

DD

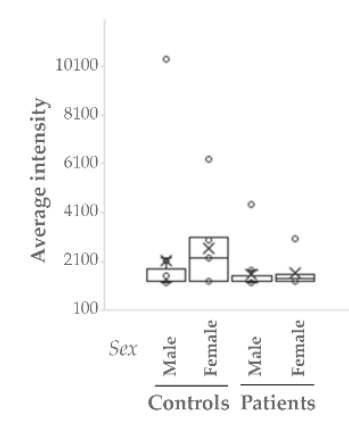

Figure 3. Western Blot analysis of uEVs in the cohort 1. A, B, C, D) Analysis of abundance of TSG101, Flotillin-1, CD10 and Syntenin-1, respectively: AA, BA, CA, DA) Non-cirrhotic (Controls) vs cirrhotic patients (t-Student, $p>0.05$ ); $\mathrm{AB}, \mathrm{BB}, \mathrm{CB}, \mathrm{DB})$ Comparison among Controls, $\mathrm{A}, \mathrm{B}$ and $\mathrm{C}$ Child-Pugh categories; $\mathrm{AC}, \mathrm{BC}, \mathrm{CC}, \mathrm{DC})$ Comparison among three age ranges from both Controls and patients; $\mathrm{AD}, \mathrm{BD}, \mathrm{CD}, \mathrm{DD})$ Comparison among male and female groups from both Controls and patients (ANOVA, $p>0.05$ in all cases). 


\subsection{Proteomics analysis of small urine EVs from cirrhotic patients and control individuals}

Next, proteomic composition of small urine EVs from controls and cirrhotic patients was determined in the cohort 2 using mass spectrometry technology (Table S2). In fact, to tailor a protein list as complete as possible, both acquisition by Synapt G2Si ESI Q-Mobility-TOF (hereafter Synapt) and LTQ Orbitrap XL ETD (hereafter Orbitrap) mass spectrometers was conducted to widely cover the proteome. EVs from 6 controls and 5 cirrhotic individuals were used for Synapt data acquisition, while 3 extra cirrhotic individuals were added for Orbitrap acquisition data. Database searches identified a totally of 1206 different proteins by the first method and 819 by the second, with 720 proteins in common (Figure 4A). From the 1206 Synapt proteins, 889 were common in controls and cirrhotic individuals, whereas 195 were exclusively detected in controls and 121 in patients (Figure 4B). With respect to Orbitrap method, from 819 proteins, 578 were identified in all individuals, whereas 99 solely in controls and 142 in patients (Figure 4C). The results also confirmed the presence of TSG101, Flotillin-1, CD10 and Syntenin1 EV markers detected by WB (Table S2).

A

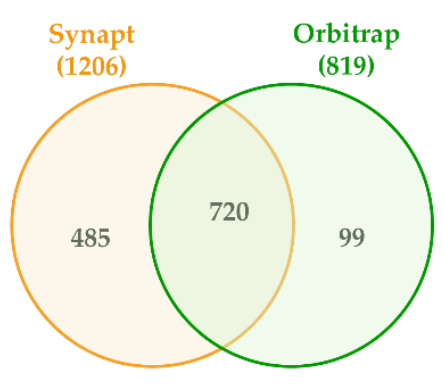

B

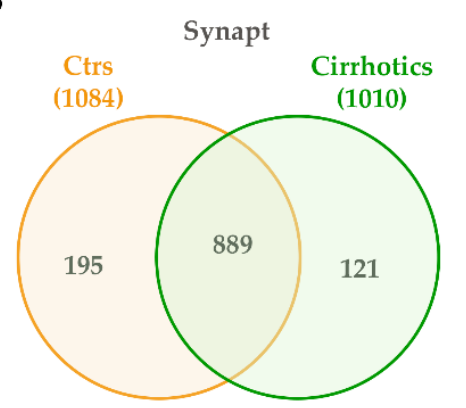

C

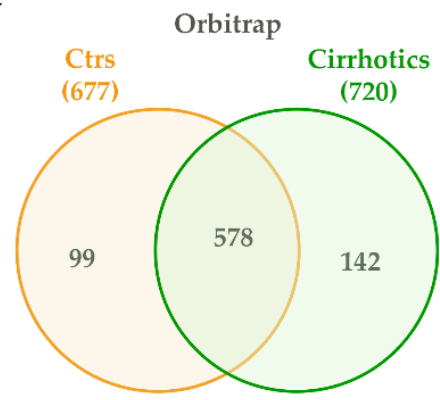

Figure 4. Venn diagrams of proteins detected in uEVs from non-cirrhotic (Controls) and cirrhotic individuals by Synapt and Orbitrat acquisition strategies. Diagrams represent the number of Uniprot/Swissprot entries identified by Mascot search engine (Matrix Science Ltd.) through Proteome Discoverer software 1.4 (Thermo).

\subsection{Differential analysis of the protein content of EVs from cirrhotic patients and control individuals}

In addition to protein identification, differential protein content between EV controls and cirrhotic was also determined. Progenesis LC-MS with an ANOVA p-value $\leq 0.05$ analysis reported a total of 59 differentially regulated proteins in cirrhotic patients vs controls. Among them, 10 differences were found by both mass spectrometers, whereas 46 and 34 were unique findings of Synapt and Orbitrap systems, respectively. As an example, TSG101, one of the EV markers tested by WB, was detected by Synapt to increase in cirrhotic pacients (Table S2). Proteins considered as differently regulated are represented by Heatmap visualization (by Perseus) (Figure 5A,B), with a total of 20 proteins described previously as putative biomarkers for liver disease (Table 2). 
A

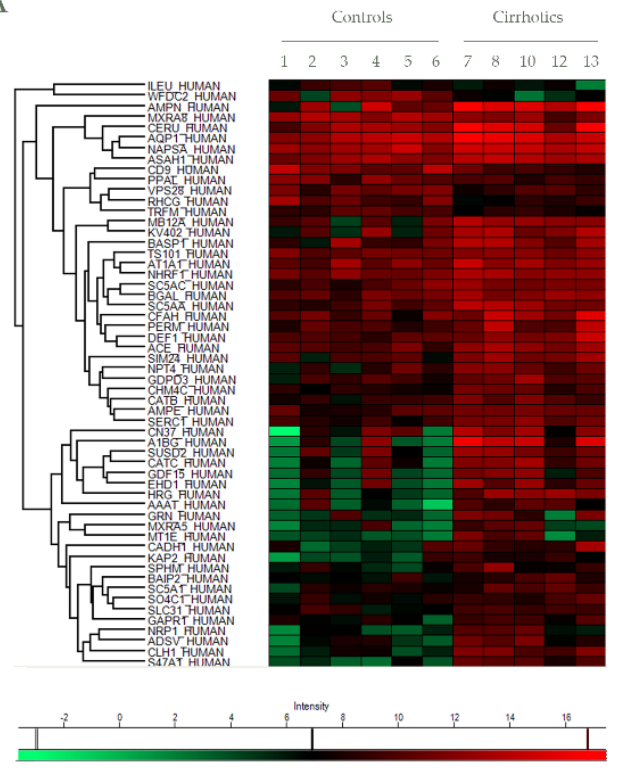

B

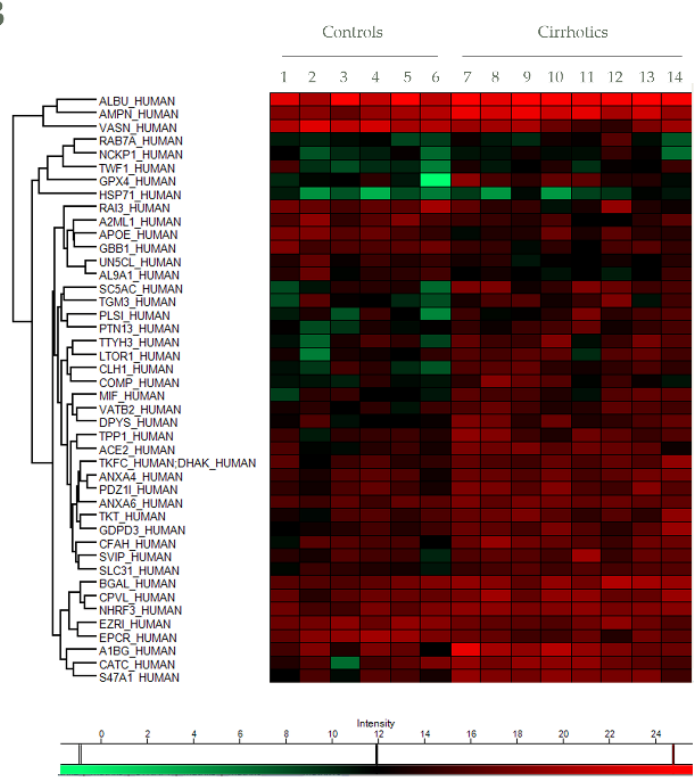

Figure 5. Heat maps for differential proteins between controls and cirrhotic patients in Synapt and Orbitrap methodologies. Hierarchical clustering of the relative abundance of A) 56 (Synapt) and B) 44 (Orbitrap) identified proteins. The vertical dendrogram represents the correlation distances between protein abundance levels (Perseus program). Colors represent the relative abundance (upregulation in red, downregulation in green). Relative abundance and raw data of each protein are included in Table S2. Only proteins identified with at least two peptides at FDR $<1 \%$ were considered in the analysis.

Table 2. Proteins differentially regulated in uEVs from cirrhotic patients that were previously described as putative biomarkers for liver disease.

\begin{tabular}{|c|c|c|c|c|c|}
\hline Accession & Specie & Molecule & Disease & Sample & References \\
\hline CLH1_HUMAN ${ }^{1}$ & Human & Protein & Cirrhosis & Liver biopsy & [30] \\
\hline \multirow[t]{3}{*}{ A1BG_HUMAN ${ }^{1}$} & Human & Protein & Chronic alcoholics liver damage & Blood lymphocytes & [31] \\
\hline & Rat & Protein & Regeneration model & Liver biopsy & [32] \\
\hline & Mice & Protein & Adenoma model & Serum & [33] \\
\hline AMPN_HUMAN² & Human & Protein & $\mathrm{HCC}$ & Liver biopsy & [34] \\
\hline ACE_HUMAN $^{2}$ & Human & Protein & ALD & Serum & [35] \\
\hline HRG_HUMAN $^{2}$ & Human & Protein & Cirrhosis & Liver biopsy & [36] \\
\hline DEF1_HUMAN ${ }^{2}$ & Human & Protein & Acute-non chronic liver failure & Serum & [37] \\
\hline CATB_HUMAN² & Human & Protein & Cirrhosis, HCC & Serum & [38] \\
\hline AMPE_HUMAN² & Human & Activity & Cirrhosis & Serum & [39] \\
\hline MT1E_HUMAN² & Human & mRNA & ALD & Blood & [40] \\
\hline GDF15_HUMAN² & Human & Protein & Chronic liver disease & Serum & [41] \\
\hline NRP1_HUMAN² & Human & Protein & $\mathrm{HCC}$ & Liver biopsy & [42] \\
\hline SUSD2_HUMAN² & Human & Protein/mRNA & $\mathrm{HCC}$ & Liver biopsy & [43] \\
\hline CERU_HUMAN² & Human & Protein & Wilson disease & Serum & [44] \\
\hline ACE2_HUMAN³ & Human & Protein & Liver disease & Serum & [45-47] \\
\hline ALBU_HUMAN³ & Human & Protein & Liver disease & Serum & {$[48,49]$} \\
\hline MIF_HUMAN ${ }^{3}$ & Human & Protein & ALD & Serum & [50] \\
\hline ANXA6_HUMAN3 & Human & RNA & $\mathrm{HCC}$ & Liver biopsy & [51] \\
\hline
\end{tabular}




\begin{tabular}{cccccc} 
EPCR_HUMAN3 & Human & Protein & Chronic liver disease & Plasma \\
RAI3_HUMAN3 & Human & Protein/mRNA & HCC & Serum & [53] \\
VASN_HUMAN3 & Human & Protein & HCC & Serum \\
COMP_HUMAN33 & Human & Protein & Cirrhosis, risk of HCC & Serum \\
\hline
\end{tabular}

${ }^{1}$ Proteins detected to be deregulated by Synapt and Orbitrap, ${ }^{2}$ only by Synapt or only by ${ }^{3}$ Orbitrap acquisition.

Functional analysis revealed a number of significantly enriched processes $(p<0.05)$ among the set of differetially expressed proteins (Figure 6). 47 of the differentially regulated proteins detected by Synapt and 10 of the ones detected by Orbitrap were shown to be involved on these significantly enriched processes. GO analysis revealed that the differential proteins are especially involved in protein traffic processes and secretion, being the endocytic system and ESCRT machinery well represented in accordance with the EVs nature. Other functions involved glycosidation, sodium transport and angiogenesis (Figure 6A, B, C).

As expected, Synapt strategy resulted in a wider list of proteins compared to Orbitrap acquisition. Accordingly, 9 out 10 enriched proceses identified after GO study on Orbitrap differential proteins were also detected by Synapt. 1 out 10, defined as blood microparticle GO cellular component and represented by ApoE, was the exception (Figure 6C).

A

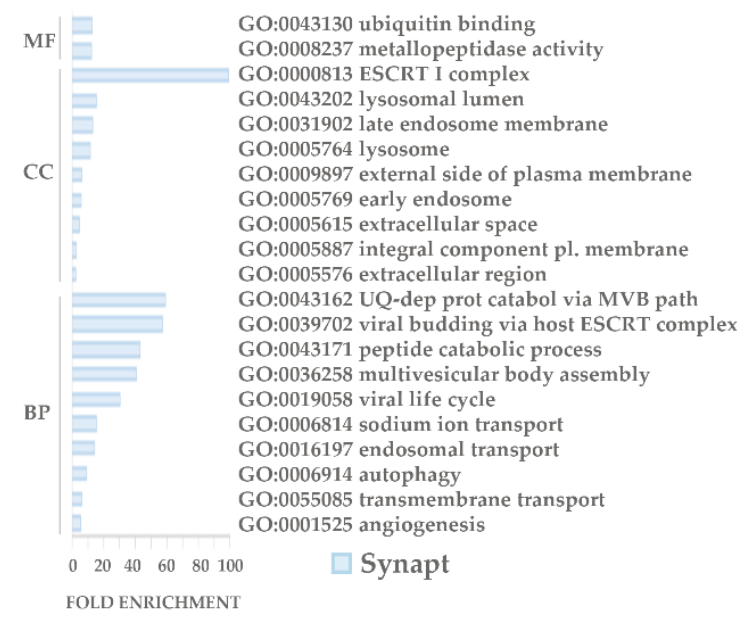

C

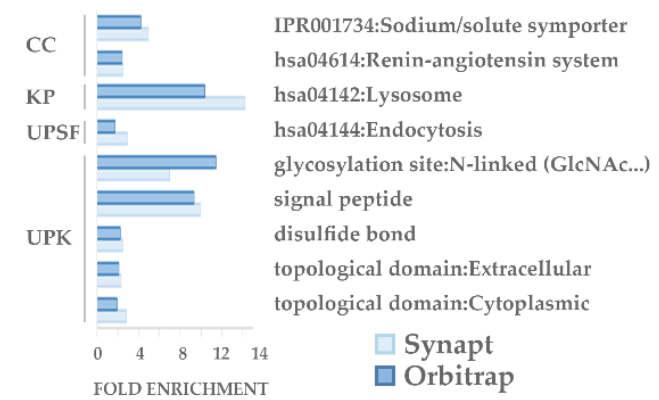

B

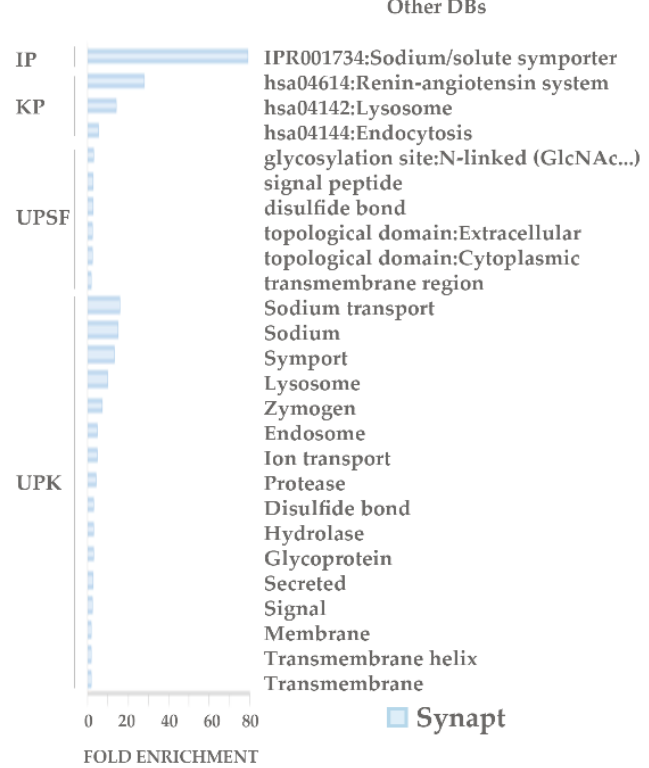

$\mathrm{D}$

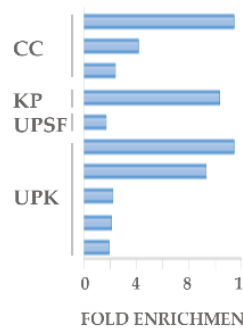

Go terms and other DBs

GO:0072562 blood microparticle GO:0005615 extracellular space GO:0005576 extracellular region hsa04142: Lysosome glycosylation site:N-linked (GlcNAc...) Zymogen Lysosome Secreted Signal Glycoprotein $\begin{array}{lllll}0 & 4 & 8 & 12 & \square \text { Orbitrap }\end{array}$

Figure 6. GO enrichment analysis. GO enrichment analysis of differentially regulated proteins between controls and patients found by Synapt and Orbitrap methodologies was performed by DAVID. The GO term or categories Molecular Function (MF), Cellular Component (CC) and 
Biological Process (BP) were assessed. Additionally, Interpro (IP), KEGG Pathways (KP), sequences (UPSF) and keywords (UPK) were also analyzed, considering terms with an enrichment $p-v a l u e<0.05$.

\section{Discussion}

Serum and plasma EVs have been largely studied as sources of biomarkers and hepatic conditions are not the exception [56,57]. Indeed, they also contribute to the function in liver [26]. However, in chronic patients, blood sampling becomes more problematic as the illness worsens. Thus, we have explored different features of hepatic EVs in our group, demonstrating the utility of urinary EVs (uEVs) to detect changes in the liver in response to toxicity [58,59].

In this work, we wondered if uEVs could serve as indicators of hepatic injury in alcoholic cirrhosis. We observed changes in the uEV population not only in terms of concentration as observed in previous studies with circulating EVs [27,60-63], but also in size (Figure 2). Both parameters seemed to be influenced by gender in opposite sense. In agreement with this, MELD clinical score also seems to be gender and age dependent (Table S1). That these two variables must be taken into consideration in ALD diagnosis and evaluation is a fact. WHO publishes that the percentage of men deaths attributable to alcohol and disability-adjusted lifeyears (DALYs) are more than twice compared to women [1]. Indeed, older men are at the highest risk to HCC development [64].

EVs allow liquid biopsy and protect biomarkers from degradation for longer time, making them more stable in injury diagnosis and assessment. Thus, well-known EV-associated proteins could also be worthy directly studying as putative indicators. In this work, TSG101, Flotillin-1, CD10 and Syntenin-1 have been shown to behave differently, suggesting that they could represent distinct uEVs populations. TSG101 and Flotillin-1 typical EV-markers have been described that are elevated in HCC patients and associated with HCC progression [65,66]. However, TSG101 and Flotillin-1 abundance did not apparently change in uEVs when compared controls vs patients (Figure 3AA, BA), though they trended to increase in cirrhotic patients $>50$ and $>70$ years old respectively. Such difference disappears when studied men and woman separately, there being greater accumulation of TSG101 and Flotillin-1 in uEVs from women. Another classical EV-protein as CD10 or Neprilysin is known to reduce abundance and change pattern in liver biopsies with advance fibrosis or presence of lobular inflammation or extensive metastases [67]. In particular, CD10 also distinguishes HCC primary tumors from secondary hepatocellular tumors [68]. A decrease tendency in this protein is also observed in this study, more evident in men and clearly when compared age groups (Figure 3C). Another EV-protein considered in this study is Syntenin-1, reported to decrease in urine from patients with mitochondria disease [69]. In accordance with this, Syntenin1 associated with uEV decreases with disease progression (Figure 3D).

Our results suggest that $\mathrm{uEV}$ proteins could act as direct biomarkers along with other more specific. Indeed, a typical EV marker, CD81, acts as receptor for hepatitis C virus and has been reported to decrease intracellularly while increasing in serum according to the severity of the disease [70,71]. CD81 is associated with differentiation and metastasis of HCC [72] and, more recently, with glucose intolerance and insulin resistance, so it is suggested as an useful index to predict the risk of future metabolic disorders or the future success of efforts to control body weigh [73].

Our proteomics analysis by using Synapt and Orbitrap acquisition reported a total of 90 putative EV-associated biomarkers for ALD, including TSG101 (Table 2S). Many of them (20) have previously been reported as putative biomarkers in liver disease (Table 2). ACE and ACE2, that orchestrate together with CD10 the Renin-angiotensin system, play an important role in metabolic syndrome and liver disease development [74,75]. Both partners have been extensively studied in liver disease and their serum levels are reported to correlate with the severity of disease [45-47]. Lately, ACE2 has aroused great interest since it is a receptor for SARS-CoV-2 entry. The fact that it is highly expressed in the gastrointestinal tract and presents elevated levels when liver disease would explain the high susceptibility of patients to SARS-CoV-2 infection [76-78]. EV- associated ACE2 has a protective activity [79,80], otherwise it can act as virus docking, endocytic pathway entry for cell infection and virus spreading [81]. Indeed, ACE2 homologue, Collectrin, has been involved in intracellular trafficking and signalling [82] and AMPN, a well-known EV-component, is a coreceptor for the virus 
[83] and recently described in HCC promotion [84]. Hence, EV-based strategies for the treatment of COVID-19 virus infection may be through inhibition of exosome biogenesis and/or EV-vaccine [85].

Renin-angiotensin system is also responsible, in part, for hypervolemic hyponatremia in cirrhosis. This syndrome is attributed to poor functional capacity of the kidneys to eliminate solutefree water, resulting in an elevated accumulation of water in relation to sodium [86]. In our study, upregulation of 5 sodium-coupled transporters in secreted $\mathrm{uEVs}$ from cirrhotic patients was observed (SC5AC, SC5AA, NPT4, SC5A1, AT1A1), maybe contributing to sodium balance. Beside this, iron is another key element in liver disease since it is accountable for ferroptosis, an iron-dependent form of cell death characterized by the loss of lipid peroxide repair activity by glutathione peroxidase 4 (GPX4) [87]. The increase in uEV-GPX4 secretion observed in our study could contribute to the whole loss of its activity when cirrhosis, becoming a putative target for therapy. Targeting ferroptosis may prevent the progression of several liver diseases, including ethanol-induced liver injury [88]. Indeed, ferroptosis-inducing therapy is being applied as treatment in many cancers by using drugs such as sorafenib, erastin and RSL3 [89], and new formulations with erastin-loaded exosomes are been explored [90]. Other upregulated uEV-proteins involved in homeostasis of molecules are RHCG, that plays a major role in transporting ammonia and accumulates in acute liver failure, resulting in brain damage [91,92]; and GDPD3, responsible for lysophosphatidic acid synthesis that, in turns, is involved in liver disease development [93-95].

Some uEVs proteins found in the proteomics analysis to be differentially regulated in cirrhotic patients such CADH1, CATC, TKT and VASH are known to promote HCC [96-99]. Others, such as WFDC2, GRN, SVIP and BGAL are reported to exert control on the disease [100-102]. In particular, BGAL is a marker of senescence that takes place during the progression of cirrhosis and HCC as part of the antitumoral response [103,104].

Multiple lines of evidence indicate that many biomarkers could change inversely proportional to the disease progression. COMP, for example, was found in our proteomics analysis to be upregulated. Importantly, it has been reported that the amount of this protein increases in early cirrhosis and then, decreases in advanced stages [105]. Finding biomarkers that assess the course of liver disease or stages and indicate the underlying etiology is highly challenging. In this line, impact of alcohol on EV contents in alcohol-related or xenobiotic exposure is an under-studied area $[29,106,107]$. Interestingly, we found MIF, that play an important role in ALD development, to be upregulated in uEV [108-110]. Indeed, EV-MIF was described to be necessary for pre-metastatic niche development in liver [111].

In this work, we have explored uEV in alcoholic cirrhosis, finding evidence that supports their use in diagnosis and assessment of the disease. However, given the high inter-individual variability found in this pilot study and EV heterogeneity, a higher number of samples would be necessary to truly establish $\mathrm{uEV}$ as a source of biomarkers for cirrhosis detection and diagnosis.

\section{Materials and Methods}

\subsection{Experimental design}

The summary of the experimental workflow can be found in the Graphical Abstract.

\subsection{Patient samples}

Urine samples and data from patients included in this study were provided by the Basque Biobank (www.biobancovasco.org), BIOEF, Basurto University Hospital) upon informed consent and with evaluation and appropriate approval of the Ethical and Scientific Committees (code CEIC 1001). Both controls and patients were evaluated for ALD. Between $6-150 \mathrm{~mL}$ of urine was collected by spontaneous micturition, centrifuged at $1,500 \times \mathrm{g} 5 \mathrm{~min}$, filtered through a $0.22 \mu \mathrm{m}$-pore membrane and immediately frozen at $-80^{\circ} \mathrm{C}$ until processing for uEVs purification.

In this study, 2 independent cohorts were used (Table 1, Table S1). Both of them included patients diagnosed with different stages of alcoholic cirrhosis, male and female genders and an age range 
between 18-83 years or 27-73 individuals respectively. The cohort 1 consisted of 21 controls and 21 cirrhotic patients where uEVs were characterized and analysed by Cryo Electron microspopy (CryoEM), Nanoparticle Tracking Analysis (NTA) and EV-markers abundance by western blotting (WB). The cohort 2 comprised urine samples donated by 6 controls and 8 patients where uEVs were submitted for proteomics analysis. For this purpose, two proteomics approaches were used by means of Synapt G2Si ESI Q-Mobility-TOF (Waters) and LTQ Orbitrap XL ETD (Thermo) spectrometers.

\subsection{Urine extracellular vesicle isolation and use}

To isolate EVs from urine, the stored samples at $-80^{\circ} \mathrm{C}$ were thawed overnight at $4^{\circ} \mathrm{C}$, centrifuged at $10,000 \times \mathrm{g}$ for $30 \mathrm{~min}$ and the supernatant ultra-centrifuged at $100,000 \times \mathrm{g}$ for $75 \mathrm{~min}$. Final pellet was re-suspended in PBS (P100), using 1:1000 of the original volume of sample, aliquot generated if necessary and kept at $-80^{\circ} \mathrm{C}$ for further analysis.

For the first cohort, $20 \mu \mathrm{L}$ were loaded for Western blotting analysis, $5 \mu$ for NTA and $5 \mu \mathrm{L}$ for CryoEM. In the case of the second cohort, 9/10 of EVs sample volume was utilized for proteomics acquisition.

\subsection{Cryo-Electron Microscopy}

For negative staining, vesicles were adsorbed onto glow-discharged Formvar-Carbon Niquel grids, washed with distilled water and stained with freshly prepared $2 \%$ uranyl acetate in aqueous suspension. Negative stained samples were imaged at room temperature using a JEM-1230 transmission electron microscope (JEOL) equipped with a thermionic tungsten filament and operated at an acceleration voltage of $120 \mathrm{kV}$. Images were taken using the ORIUS SC1000 (4008 $\times 2672$ pixels) cooled slow-scan CCD camera (GATAN). For cryo-electron microscopy, EV preparations were directly adsorbed onto glow-discharged holey carbon grids (QUANTIFOIL, Germany). Grids were blotted at $95 \%$ humidity and rapidly plunged into liquid ethane with the aid of a VITROBOT (Maastricht Instruments BV, The Netherlands). Vitrified samples were imaged at liquid nitrogen temperature using a JEM-2200FS/CR transmission cryo-electron microscope (JEOL, Japan) equipped with a field emission gun and operated at an acceleration voltage of $200 \mathrm{kV}$.

\subsection{Nanoparticle tracking analysis (NTA)}

Size distribution of the uEVs preparations was determined by measuring the Brownian motion using a NanoSight LM10 system equipped with a fast video capture and particle-tracking software (Malvern, UK). Pre- and post-acquisition settings were maintained the same for all the samples and each video was analyzed to give the mode for particle size as well as an estimate of the particle concentration. Each sample was acquired 5 times. Then, an average curve was calculated for each sample. Comparative analysis between or among groups was performed by means of $t$-Student or ANOVA respectively.

\subsection{Western blot (WB) analysis}

For each sample, $15 \mu \mathrm{L}$ of PBS-resuspended EVs were mixed with NuPAGE LDS Sample Buffer (Invitrogen by Thermo Scientific). The samples were incubated for $5 \mathrm{~min}$ at $37^{\circ} \mathrm{C}, 10 \mathrm{~min}$ at $65^{\circ} \mathrm{C}$, and $15 \mathrm{~min}$ at $95^{\circ} \mathrm{C}$, centrifuged at $20000 \mathrm{~g}$ for $15 \mathrm{~min}$ and supernatant separated on NuPAGE $4-12 \%$ pre-casted gels (Invitrogen by Thermo Scientific). Proteins were transferred to a PVDF membrane (Millipore by Merck) that was then blocked for $1 \mathrm{~h}$ in 5\% milk and $0.05 \%$ Tween-20 in PBS. Then, the membrane was incubated overnight at $4{ }^{\circ} \mathrm{C}$ with the primary antibody, followed by PBS washing before application of the corresponding secondary HRP-conjugated antibody. Chemiluminescent bands were detected with Pierce ${ }^{\mathrm{TM}}$ ECL Plus Western Blotting Substrate (Pierce by Thermo Scientific). Mouse monoclonal antibodies were purchased from the following vendors: mouse monoclonal antibody against TSG101 (clone 4A10) was obtained from Abcam, against Flotillin-1 (clon 18) and Rab27 (clon 20) from BD Biosciences, for CD10 (Neprilysin, clon F-4) and Glypican-1 (A-10) from Santa Cruz Biotechnology, Inc., and for CD63 (clon H5C6), CD81 (clon JS81) and EpCAM (clon G8.8) 
from Hybridoma Bank. Rabbit polyclonal antibody against Syntenin-1 (clon C2C3) was purchased from GeneTex, Caveolin-1 (ab2910) and Syndecan4 (ab24511) from Abcam, AQP1 (A5560) and AQP2 (A7310) from Sigma.

Signal for each protein was quantified by densitometry by using the ImageQuant image software. Comparative analysis between or among groups was performed by means of $t$-Student or ANOVA respectively.

\subsection{Proteomics}

\subsubsection{In solution digestion}

Protein was extracted using 7M urea, $2 \mathrm{M}$ thiourea, $4 \%$ CHAPS. Samples were incubated for $30 \mathrm{~min}$ at RT under agitation and digested following the filter-aided FASP protocol described by Wisniewski et al [112] with minor modifications. Trypsin was added to a trypsin:protein ratio of 1:10, and the mixture was incubated overnight at $37 \mathrm{oC}$, dried out in a RVC2 25 speedvac concentrator (Christ), and resuspended in $0.1 \% \mathrm{FA}$.

\subsubsection{LC - MS analysis}

LC was performed using a NanoAcquity nano-HPLC (Waters), equipped with a Waters BEH C18 nano-column (200mm x 75 um ID, 1.8um). A chromatographic ramp of $120 \mathrm{~min}$. (5 to $60 \% \mathrm{ACN}$ ) was used with a flow rate of $300 \mathrm{nl} / \mathrm{min}$. Mobile phase A was water containing $0.1 \% \mathrm{v} / \mathrm{v}$ formic acid, while mobile phase B was ACN containing $0.1 \% \mathrm{v} / \mathrm{v}$ formic acid.

Samples were acquired using two different mass spectrometers. On the one hand, a Synapt G2Si ESI Q-Mobility-TOF spectrometer (Waters) equipped with an ion mobility chamber (T-Wave-IMS) for high-definition data acquisition analyses was used. All analyses were performed in positive mode ESI. Data were post-acquisition lock mass corrected using the double charged monoisotopic ion of [Glu1]-Fibrinopeptide B. Accurate mass LC-MS data were collected in HDDA mode that enhances signal intensities using the ion mobility separation step. On the other hand, sample was also loaded onto an LTQ Orbitrap XL ETD (Thermo). This mass spectrometer automatically switched between MS and MS/MS acquisition in DDA mode. Full MS scan survey spectra (m/z 400-2000) were acquired in the orbitrap with mass resolution of 30000 at $\mathrm{m} / \mathrm{z} 400$. After each survey scan, the six most intense ions above 1000 counts were sequentially subjected to collision-induced dissociation (CID) in the linear ion trap. Precursors with charge states of 2 and 3 were specifically selected for CID. Peptides were excluded from further analysis during $60 \mathrm{~s}$ using the dynamic exclusion feature.

\subsection{Bioinformatics}

\subsubsection{Database searches and protein identification}

Searches were carried out using Mascot search engine (Matrix Science Ltd.) through Proteome Discoverer software 1.4 (Thermo). Orbitrap RAW files were directly loaded into the program, whereas mgf files generated by DataAnalysis software (Bruker) were used for timsTOF searches. Orbitrap searches were carried out with precursor and fragment tolerances of $10 \mathrm{ppm}$ and $0.5 \mathrm{Da}$, whereas 50ppm and 0.05Da were used for TIMS TOF runs. A database consisting of human entries (Uniprot/Swissprot) was used for the searches. Only proteins identified with at least two peptides at $\mathrm{FDR}<1 \%$ in at least two sample replicas and not present in the negative control were considered for further analysis. InteractiveVenn (http://www.interactivenn.net/) was used for making Venn diagrams.

\subsubsection{Differential protein content analysis}

Progenesis LC-MS (version 4.2.7207.22925, Nonlinear Dynamics) was used for the label-free differential protein content analysis. One of the runs was used as the reference to which the precursor masses in all other samples were aligned to. Only features comprising charges of $2+$ and $3+$ were 
selected. The raw abundances of each feature were automatically normalized and logarithmized against the reference run. Samples were grouped in accordance with the comparison being performed, and an ANOVA analysis was performed. A peak list containing the information of all the features was generated and exported to the Mascot search engine (Matrix Science Ltd.). This file was searched against a Uniprot/Swissprot database, and the list of identified peptides was imported back to Progenesis LC-MS. Protein quantitation was performed based on the three most intense nonconflicting peptides (peptides occurring in only one protein), except for proteins with only two nonconflicting peptides. The significance of expression changes was tested at protein level, and proteins with an ANOVA p-value $\leq 0.05$ were selected for further analyses. Heatmaps were generated using Perseus software [113].

\subsubsection{Functional analysis}

GO enrichment analysis was carried out using the DAVID online tool (http://david.abcc.ncifcrf.gov/summary.jsp) [114]. DAVID is a GO Term annotation and enrichment analysis tool used to highlight the most relevant GO terms associated with a given gene list. A Fisher Exact test is used in order to determine whether the proportion of genes considered into certain GO term or categories differ significantly between the dataset and the background. Biological Process (BP), Molecular Function (MF) and Cellular Component (CC) categories were assessed. Additionally, KEGG Pathways, keywords, sequences, and Interpro and Smart databases were also analyzed, considering terms with an enrichment $\mathrm{p}$-value $<0.05$.

\section{Conclusions}

Accurate diagnosis and assessment of ALD is challenging, particularly because of the difficulty of identifying early stages of the disease before fibrosis progresses to develop cirrhosis and/or HCC. Additionally, there is no unique clinical presentation of ALD that can be distinguished with certainty from other forms of liver disease. Proteomics, genomics and metabolomics approaches could also help identify the etiology of liver disease $[115,116]$ and, in case of ALD, even understand the detoxification mechanisms of alcohol [117]. In this line, liquid biopsy approaches, as EVs, provide great knowledge and could become useful tools. In our study, changes in concentration and size, as well as in composition have been observed in uEVs from cirrhotic patients. Supporting also the value of EVs in ALD diagnosis, Sehrawat et al, 2020 made the observation that circulating EV concentration and sphingolipid cargo signature could diagnose and differentiate $\mathrm{AH}$ from heavy drinkers, decompensated AC, and other etiologies of ESLD. Other authors also described changes when ALD in circulating EVs concentration $[27,61-63]$, certain miRNAs $[27,63,118]$ and hepatic proteins such as ALB, HP, FGB, CYP2E1, 2A, 1A1/2, 4B [61,62]. For HCC diagnosis, new EVs-based approaches that allow easy and standardized use in clinical settings are being studied [119].

Sampling selection and management in liquid biopsy is key to diagnosis. In this sense, urine could become an appropriate alternative for sampling in diagnosis and EV-isolation in chronic patients, although this fluid presents several limitations that must be solved. We have found several obstacles along this work, such as the impossibility of quantifying the amount of protein in EVisolates because of the urine $\mathrm{pH}$, leading to explain the data on the basis of sample volume instead of on protein concentration. Furthermore, the lack of standardized protocols for sample collection introduces some uncontrollable variables. Apart from addressing these questions, also more numerous cohorts of individuals, containing similar number of individuals of either gender, in the distinct ranges of age and Child-Pugh categories for cirrhosis are needed to obtain more definitive conclusions.

Supplementary Materials: The following material is available online at www.mdpi.com/xxx/s1, Table S1: Clinical samples, Table S2: Proteomics.

Table S1. Clinical samples. (excel document). Non-cirrhotic (controls) and cirrhotic individuals included in the study in both independent cohorts (Cohort 1 and Cohort 2). The table contains age (years), gender and the clinical scores for cirrhosis assessment Model of End-Stage Liver Disease (MELD) and Child-Pugh. 
Table S2. Proteomics. (excel document). The spreadsheets Synapt-Mascot and Orbitrap-Mascot contain the individual and total spectral counts of all the identified proteins according to the corresponding spectrometer. Similarly, the spreadsheets Synapt-PG and Orbitrap-PG contain the raw and normalized abundance values and statistic parameters attained from differential analysis between non-cirrhotic and cirrhotic individuals through Progenesis software. The spreadsheet Differential Proteins-PG shows the complete list of differentially regulated proteins: in green, those that are detected by both Synapt and Orbitrap acquisition to be deregulated $(p<0.05)$; in light blue, those that are detected by Synapt $(p<0.05)$; and in dark blue, those detected by Orbitrap $(p<0.05)$. Without color, those detected with an ANOVA $p \geq 0.05$.

Author Contributions: Study concept and design: E.G. and J.M.F. Acquisition of data: E.G., M.A., C.G., J.P. and S.B. Analysis and interpretation of data: E.G., M.A. and J.M.F. Drafting of the manuscript: E.G. Critical revision of the manuscript for important intellectual content: E.G., M.A., F.E., S.B. and J.M.F. Study supervision and funding acquisition: J.M.F. All authors have read and agreed to the published version of the manuscript.

Funding: This research was funded by the project RTI2018-094969-B-I00 (MCIU/AEI/FEDER, UE) and Excellence Severo Ochoa Grant (SEV-2016-0644), and by the European Union's Horizon 2020 research.

Acknowledgments: We thank to Idoia Iturrioz, Isaac Santos and Adriana L Rojas from Electron Microscopy Platform in CIC bioGUNE for the Cryo-EM images; and to Basque Biobank (www.biobancovasco.org), BIOEF, Basurto University hospital for helping with all the aspects regarding storage and shipments of the clinical samples.

Conflicts of Interest: “The authors declare no conflict of interest."

\section{References}

1. WHO. Global status report on alcohol and health 2018 (World Health Organization, 2018). 2018.

2. Shield, K.D.; Parry, C.; Rehm, J. Chronic diseases and conditions related to alcohol use. Alcohol Res 2013, $35,155-173$.

3. Rehm, J.; Gmel, G.E., Sr.; Gmel, G.; Hasan, O.S.M.; Imtiaz, S.; Popova, S.; Probst, C.; Roerecke, M.; Room, R.; Samokhvalov, A.V., et al. The relationship between different dimensions of alcohol use and the burden of disease-an update. Addiction 2017, 112, 968-1001, doi:10.1111/add.13757.

4. Gao, B.; Bataller, R. Alcoholic liver disease: pathogenesis and new therapeutic targets. Gastroenterology 2011, 141, 1572-1585, doi:10.1053/j.gastro.2011.09.002.

5. Mathurin, P.; Bataller, R. Trends in the management and burden of alcoholic liver disease. J Hepatol 2015, 62, S38-46, doi:10.1016/j.jhep.2015.03.006.

6. Thursz, M.; Gual, A.; Lackner, C.; Mathurin, P.; Moreno, C.; Spahr, L.; Sterneck, M.; Cortez-Pinto, H. EASL Clinical Practice Guidelines: Management of alcohol-relted liver disease. J Hepatol 2018, 69, 154181, doi:10.1016/j.jhep.2018.03.018.

7. Seitz, H.K.; Mueller, S. Alcoholic Liver Disease. In Clinical Hepatology, Springer, B., Heidelberg., Ed. 2010.

8. Tsochatzis, E.A.; Bosch, J.; Burroughs, A.K. Liver cirrhosis. Lancet 2014, 383, 1749-1761, doi:10.1016/s0140-6736(14)60121-5.

9. Bruha, R.; Dvorak, K.; Petrtyl, J. Alcoholic liver disease. World J Hepatol 2012, 4, 81-90, doi:10.4254/wjh.v4.i3.81.

10. Rehm, J.; Mathers, C.; Popova, S.; Thavorncharoensap, M.; Teerawattananon, Y.; Patra, J. Global burden of disease and injury and economic cost attributable to alcohol use and alcohol-use disorders. Lancet 2009, 373, 2223-2233, doi:10.1016/s0140-6736(09)60746-7.

11. Dugum, M.; McCullough, A. Diagnosis and Management of Alcoholic Liver Disease. J Clin Transl Hepatol 2015, 3, 109-116, doi:10.14218/jcth.2015.00008.

12. Torruellas, C.; French, S.W.; Medici, V. Diagnosis of alcoholic liver disease. World J Gastroenterol 2014, 20, 11684-11699, doi:10.3748/wjg.v20.i33.11684. 
13. Addolorato, G.; Vassallo, G.A.; Mirijello, A.; Gasbarrini, A. Diagnosis and Management of Alcohol Use Disorder in Patients with Liver Disease: Lights and Shadows. Neurotherapeutics 2020, 17, 127-141, doi:10.1007/s13311-019-00802-8.

14. Seitz, H.K.; Bataller, R.; Cortez-Pinto, H.; Gao, B.; Gual, A.; Lackner, C.; Mathurin, P.; Mueller, S.; Szabo, G.; Tsukamoto, H. Alcoholic liver disease. Nat Rev Dis Primers 2018, 4, 16, doi:10.1038/s41572-018-00147.

15. Rudler, M.; Mouri, S.; Charlotte, F.; Cluzel, P.; Ngo, Y.; Munteanu, M.; Lebray, P.; Ratziu, V.; Thabut, D.; Poynard, T. Validation of AshTest as a Non-Invasive Alternative to Transjugular Liver Biopsy in Patients with Suspected Severe Acute Alcoholic Hepatitis. PLoS One 2015, 10, e0134302, doi:10.1371/journal.pone.0134302.

16. Hadefi, A.; Degré, D.; Trépo, E.; Moreno, C. Noninvasive diagnosis in alcohol-related liver disease. In Health Sci Rep, (C) 2020 The Authors. Health Science Reports published by Wiley Periodicals, Inc.: 2020; Vol. 3, p. e146.

17. Gala, K.S.; Vatsalya, V. Emerging Noninvasive Biomarkers, and Medical Management Strategies for Alcoholic Hepatitis: Present Understanding and Scope. Cells 2020, 9, doi:10.3390/cells9030524.

18. Bianchi, L. Liver biopsy in elevated liver functions tests? An old question revisited. In J Hepatol, Netherlands, 2001; Vol. 35, pp. 290-294.

19. Lupsor-Platon, M.; Badea, R. Noninvasive assessment of alcoholic liver disease using unidimensional transient elastography (Fibroscan $\left({ }^{\circledR}\right)$ ). World J Gastroenterol 2015, 21, 11914-11923, doi:10.3748/wjg.v21.i42.11914.

20. Kummer, N.; Lambert, W.E.; Samyn, N.; Stove, C.P. Alternative sampling strategies for the assessment of alcohol intake of living persons. Clin Biochem 2016, 49, 1078-1091, doi:10.1016/j.clinbiochem.2016.05.007.

21. Svenningsen, P.; Sabaratnam, R.; Jensen, B.L. Urinary extracellular vesicles: Origin, role as intercellular messengers and biomarkers; efficient sorting and potential treatment options. Acta Physiol (Oxf) 2020, 228, e13346, doi:10.1111/apha.13346.

22. Yáñez-Mó, M.; Siljander, P.R.; Andreu, Z.; Zavec, A.B.; Borràs, F.E.; Buzas, E.I.; Buzas, K.; Casal, E.; Cappello, F.; Carvalho, J., et al. Biological properties of extracellular vesicles and their physiological functions. J Extracell Vesicles 2015, 4, 27066, doi:10.3402/jev.v4.27066.

23. González, E.; Falcón-Pérez, J.M. Cell-derived extracellular vesicles as a platform to identify lowinvasive disease biomarkers. Expert Rev Mol Diagn 2015, 15, 907-923, doi:10.1586/14737159.2015.1043272.

24. Simeone, P.; Bologna, G.; Lanuti, P.; Pierdomenico, L.; Guagnano, M.T.; Pieragostino, D.; Del Boccio, P.; Vergara, D.; Marchisio, M.; Miscia, S., et al. Extracellular Vesicles as Signaling Mediators and Disease Biomarkers across Biological Barriers. Int J Mol Sci 2020, 21, doi:10.3390/ijms21072514.

25. Szabo, G.; Momen-Heravi, F. Extracellular vesicles in liver disease and potential as biomarkers and therapeutic targets. Nat Rev Gastroenterol Hepatol 2017, 14, 455-466, doi:10.1038/nrgastro.2017.71.

26. Azparren-Angulo, M.; Royo, F.; Gonzalez, E.; Liebana, M.; Brotons, B.; Berganza, J.; Goñi-de-Cerio, F.; Manicardi, N.; Abad-Jordà, L.; Gracia-Sancho, J., et al. Extracellular vesicles in hepatology: Physiological role, involvement in pathogenesis, and therapeutic opportunities. Pharmacol Ther 2020, 107683, doi:10.1016/j.pharmthera.2020.107683.

27. Momen-Heravi, F.; Saha, B.; Kodys, K.; Catalano, D.; Satishchandran, A.; Szabo, G. Increased number of circulating exosomes and their microRNA cargos are potential novel biomarkers in alcoholic hepatitis. J Transl Med 2015, 13, 261, doi:10.1186/s12967-015-0623-9. 
28. Hernández, A.; Arab, J.P.; Reyes, D.; Lapitz, A.; Moshage, H.; Bañales, J.M.; Arrese, M. Extracellular Vesicles in NAFLD/ALD: From Pathobiology to Therapy. Cells 2020, 9, doi:10.3390/cells9040817.

29. Cho, Y.E.; Song, B.J.; Akbar, M.; Baek, M.C. Extracellular vesicles as potential biomarkers for alcoholand drug-induced liver injury and their therapeutic applications. Pharmacol Ther 2018, 187, 180-194, doi:10.1016/j.pharmthera.2018.03.009.

30. Di Tommaso, L.; Destro, A.; Fabbris, V.; Spagnuolo, G.; Laura Fracanzani, A.; Fargion, S.; Maggioni, M.; Patriarca, C.; Maria Macchi, R.; Quagliuolo, M., et al. Diagnostic accuracy of clathrin heavy chain staining in a marker panel for the diagnosis of small hepatocellular carcinoma. Hepatology 2011, 53, 1549-1557, doi:10.1002/hep.24218.

31. Stefanini, G.F.; Mazzetti, M.; Zunarelli, P.; Piccinini, G.; Amorati, P.; Capelli, S.; Cicognani, G.; Gasbarrini, G. In vivo effect of chronic ethanol abuse on membrane alpha 1-glycoprotein of lymphocytes and immune response to various stimulating agents. Alcohol Clin Exp Res 1989, 13, 444448, doi:10.1111/j.1530-0277.1989.tb00351.x.

32. Wang, W.B.; Fan, J.M.; Zhang, X.L.; Xu, J.; Yao, W. Serial expression analysis of liver regenerationrelated genes in rat regenerating liver. Mol Biotechnol 2009, 43, 221-231, doi:10.1007/s12033-009-9199-z.

33. Sugihara, T.; Tanaka, S.; Braga-Tanaka, I., 3rd; Murano, H.; Nakamura-Murano, M.; Komura, J.I. Screening of biomarkers for liver adenoma in low-dose-rate $\gamma$-ray-irradiated mice. Int J Radiat Biol 2018, 94, 315-326, doi:10.1080/09553002.2018.1439193.

34. Yamanaka, C.; Wada, H.; Eguchi, H.; Hatano, H.; Gotoh, K.; Noda, T.; Yamada, D.; Asaoka, T.; Kawamoto, K.; Nagano, H., et al. Clinical significance of CD13 and epithelial mesenchymal transition (EMT) markers in hepatocellular carcinoma. Jpn J Clin Oncol 2018, 48, 52-60, doi:10.1093/jjco/hyx157.

35. Borowsky, S.A.; Lieberman, J.; Strome, S.; Sastre, A. Elevation of serum angiotensin-converting enzyme level. Occurrence in alcoholic liver disease. Arch Intern Med 1982, 142, 893-895.

36. Leebeek, F.W.; Kluft, C.; Knot, E.A.; De Maat, M.P. Histidine-rich glycoprotein is elevated in mild liver cirrhosis and decreased in moderate and severe liver cirrhosis. J Lab Clin Med 1989, 113, 493-497.

37. Mani, I.; Alexopoulou, A.; Vasilieva, L.; Hadziyannis, E.; Agiasotelli, D.; Bei, M.; Alexopoulos, T.; Dourakis, S.P. Human beta-defensin-1 is a highly predictive marker of mortality in patients with acuteon-chronic liver failure. Liver Int 2019, 39, 299-306, doi:10.1111/liv.13977.

38. Leto, G.; Tumminello, F.M.; Pizzolanti, G.; Montalto, G.; Soresi, M.; Gebbia, N. Lysosomal cathepsins B and $\mathrm{L}$ and Stefin A blood levels in patients with hepatocellular carcinoma and/or liver cirrhosis: potential clinical implications. Oncology 1997, 54, 79-83, doi:10.1159/000227666.

39. Megias, M.J.; Alba-Araguez, F.; Luna, J.D.; Vives, F.; Ramirez-Sanchez, M. Serum pyroglutamyl aminopeptidase activity: a promising novel biomarker candidate for liver cirrhosis. Endocr Regul 2015, 49, 20-24, doi:10.4149/endo_2015_01_20.

40. Grasselli, E.; Compalati, A.D.; Voci, A.; Vecchione, G.; Ragazzoni, M.; Gallo, G.; Borro, P.; Sumberaz, A.; Testino, G.; Vergani, L. Altered oxidative stress/antioxidant status in blood of alcoholic subjects is associated with alcoholic liver disease. Drug Alcohol Depend 2014, 143, 112-119, doi:10.1016/j.drugalcdep.2014.07.013.

41. Lee, E.S.; Kim, S.H.; Kim, H.J.; Kim, K.H.; Lee, B.S.; Ku, B.J. Growth Differentiation Factor 15 Predicts Chronic Liver Disease Severity. Gut Liver 2017, 11, 276-282, doi:10.5009/gnl16049.

42. Lin, J.; Zhang, Y.; Wu, J.; Li, L.; Chen, N.; Ni, P.; Song, L.; Liu, X. Neuropilin 1 (NRP1) is a novel tumor marker in hepatocellular carcinoma. Clin Chim Acta 2018, 485, 158-165, doi:10.1016/j.cca.2018.06.046. 
43. Liu, X.R.; Cai, C.X.; Luo, L.M.; Zheng, W.L.; Shi, R.; Zeng, J.; Xu, Y.Q.; Wei, M.; Ma, W.L. Decreased expression of Sushi Domain Containing 2 correlates to progressive features in patients with hepatocellular carcinoma. Cancer Cell Int 2016, 16, 15, doi:10.1186/s12935-016-0286-5.

44. Cauza, E.; Maier-Dobersberger, T.; Polli, C.; Kaserer, K.; Kramer, L.; Ferenci, P. Screening for Wilson's disease in patients with liver diseases by serum ceruloplasmin. J Hepatol 1997, 27, 358-362, doi:10.1016/s0168-8278(97)80182-1.

45. Miranda, A.S.; Simões, E.S.A.C. Serum levels of angiotensin converting enzyme as a biomarker of liver fibrosis. World J Gastroenterol 2017, 23, 8439-8442, doi:10.3748/wjg.v23.i48.8439.

46. Casey, S.; Schierwagen, R.; Mak, K.Y.; Klein, S.; Uschner, F.; Jansen, C.; Praktiknjo, M.; Meyer, C.; Thomas, D.; Herath, C., et al. Activation of the Alternate Renin-Angiotensin System Correlates with the Clinical Status in Human Cirrhosis and Corrects Post Liver Transplantation. J Clin Med 2019, 8, doi:10.3390/jcm8040419.

47. Ye, G.; Qin, Y.; Lu, X.; Xu, X.; Xu, S.; Wu, C.; Wang, X.; Wang, S.; Pan, D. The association of reninangiotensin system genes with the progression of hepatocellular carcinoma. Biochem Biophys Res Commun 2015, 459, 18-23, doi:10.1016/j.bbrc.2015.02.030.

48. Carvalho, J.R.; Verdelho Machado, M. New Insights About Albumin and Liver Disease. Ann Hepatol 2018, 17, 547-560, doi:10.5604/01.3001.0012.0916.

49. Spinella, R.; Sawhney, R.; Jalan, R. Albumin in chronic liver disease: structure, functions and therapeutic implications. Hepatol Int 2016, 10, 124-132, doi:10.1007/s12072-015-9665-6.

50. Kumagi, T.; Akbar, F.; Horiike, N.; Onji, M. Increased serum levels of macrophage migration inhibitory factor in alcoholic liver diseases and their expression in liver tissues. Clin Biochem 2001, 34, 189-193, doi:10.1016/s0009-9120(01)00214-4.

51. Meier, E.M.; Rein-Fischboeck, L.; Pohl, R.; Wanninger, J.; Hoy, A.J.; Grewal, T.; Eisinger, K.; Krautbauer, S.; Liebisch, G.; Weiss, T.S., et al. Annexin A6 protein is downregulated in human hepatocellular carcinoma. Mol Cell Biochem 2016, 418, 81-90, doi:10.1007/s11010-016-2735-9.

52. Biguzzi, E.; Franchi, F.; Bucciarelli, P.; Colombo, M.; Romeo, R. Endothelial protein C receptor plasma levels increase in chronic liver disease, while thrombomodulin plasma levels increase only in hepatocellular carcinoma. Thromb Res 2007, 120, 289-293, doi:10.1016/j.thromres.2006.09.009.

53. Zheng, J.; Guo, X.; Gao, X.; Liu, H.; Tu, Y.; Zhang, Y. Overexpression of retinoic acid-induced protein 3 predicts poor prognosis for hepatocellular carcinoma. Clin Transl Oncol 2014, 16, 57-63, doi:10.1007/s12094-013-1040-2.

54. Li, S.; Li, H.; Yang, X.; Wang, W.; Huang, A.; Li, J.; Qin, X.; Li, F.; Lu, G.; Ding, H., et al. Vasorin is a potential serum biomarker and drug target of hepatocarcinoma screened by subtractive-EMSA-SELEX to clinic patient serum. Oncotarget 2015, 6, 10045-10059, doi:10.18632/oncotarget.3541.

55. Zachou, K.; Gabeta, S.; Gatselis, N.K.; Norman, G.L.; Dalekos, G.N. Cartilage oligomeric matrix protein on the spot for liver fibrosis evaluation: Too early or too late? Eur J Intern Med 2017, 43, e48-e49, doi:10.1016/j.ejim.2017.05.003.

56. Povero, D.; Yamashita, H.; Ren, W.; Subramanian, M.G.; Myers, R.P.; Eguchi, A.; Simonetto, D.A.; Goodman, Z.D.; Harrison, S.A.; Sanyal, A.J., et al. Characterization and Proteome of Circulating Extracellular Vesicles as Potential Biomarkers for NASH. Hepatol Commun 2020, 4, 1263-1278, doi:10.1002/hep4.1556.

57. Uzzaman, A.; Zhang, X.; Qiao, Z.; Zhan, H.; Sohail, A.; Wahid, A.; Shang, Z.; Guan, X.; Cao, C.X.; Xiao, $\mathrm{H}$. Discovery of small extracellular vesicle proteins from human serum for liver cirrhosis and liver cancer. Biochimie 2020, 177, 132-141, doi:10.1016/j.biochi.2020.08.013. 
58. Conde-Vancells, J.; Rodriguez-Suarez, E.; Gonzalez, E.; Berisa, A.; Gil, D.; Embade, N.; Valle, M.; Luka, Z.; Elortza, F.; Wagner, C., et al. Candidate biomarkers in exosome-like vesicles purified from rat and mouse urine samples. Proteomics Clin Appl 2010, 4, 416-425, doi:10.1002/prca.200900103.

59. Rodriguez-Suarez, E.; Gonzalez, E.; Hughes, C.; Conde-Vancells, J.; Rudella, A.; Royo, F.; Palomo, L.; Elortza, F.; Lu, S.C.; Mato, J.M., et al. Quantitative proteomic analysis of hepatocyte-secreted extracellular vesicles reveals candidate markers for liver toxicity. Journal of Proteomics 2014, 103, 227 240, doi:10.1016/j.jprot.2014.04.008.

60. Payancé, A.; Silva-Junior, G.; Bissonnette, J.; Tanguy, M.; Pasquet, B.; Levi, C.; Roux, O.; Nekachtali, O.; Baiges, A.; Hernández-Gea, V., et al. Hepatocyte microvesicle levels improve prediction of mortality in patients with cirrhosis. Hepatology 2018, 68, 1508-1518, doi:10.1002/hep.29903.

61. Cho, Y.E.; Mezey, E.; Hardwick, J.P.; Salem, N., Jr.; Clemens, D.L.; Song, B.J. Increased ethanol-inducible cytochrome P450-2E1 and cytochrome P450 isoforms in exosomes of alcohol-exposed rodents and patients with alcoholism through oxidative and endoplasmic reticulum stress. Hepatol Commun 2017, 1, 675-690, doi:10.1002/hep4.1066.

62. Cho, Y.E.; Im, E.J.; Moon, P.G.; Mezey, E.; Song, B.J.; Baek, M.C. Increased liver-specific proteins in circulating extracellular vesicles as potential biomarkers for drug- and alcohol-induced liver injury. PLoS One 2017, 12, e0172463, doi:10.1371/journal.pone.0172463.

63. Eguchi, A.; Lazaro, R.G.; Wang, J.; Kim, J.; Povero, D.; Willliams, B.; Ho, S.B.; Stärkel, P.; Schnabl, B.; Ohno-Machado, L., et al. Extracellular vesicles released by hepatocytes from gastric infusion model of alcoholic liver disease contain a MicroRNA barcode that can be detected in blood. Hepatology 2017, 65, 475-490, doi:10.1002/hep.28838.

64. Yi, S.W.; Choi, J.S.; Yi, J.J.; Lee, Y.H.; Han, K.J. Risk factors for hepatocellular carcinoma by age, gender, and liver disorder status: A prospective cohort study in Korea. Cancer 2018, 124, 2748-2757, doi:10.1002/cncr.31406.

65. Liu, Z.; Tian, Z.; Cao, K.; Zhang, B.; Wen, Q.; Zhou, X.; Yang, W.; Wang, T.; Shi, H.; Wang, R. TSG101 promotes the proliferation, migration and invasion of hepatocellular carcinoma cells by regulating the PEG10. J Cell Mol Med 2019, 23, 70-82, doi:10.1111/jcmm.13878.

66. Zhang, S.H.; Wang, C.J.; Shi, L.; Li, X.H.; Zhou, J.; Song, L.B.; Liao, W.T. High Expression of FLOT1 Is Associated with Progression and Poor Prognosis in Hepatocellular Carcinoma. PLoS One 2013, 8, e64709, doi:10.1371/journal.pone.0064709.

67. Shousha, S.; Gadir, F.; Peston, D.; Bansi, D.; Thillainaygam, A.V.; Murray-Lyon, I.M. CD10 immunostaining of bile canaliculi in liver biopsies: change of staining pattern with the development of cirrhosis. Histopathology 2004, 45, 335-342, doi:10.1111/j.1365-2559.2004.01927.x.

68. Singha, J.; Khan, K.; Chatterjee, S. Diagnostic utility of CD10 immunohistochemical staining on cellblock in differentiating hepatocellular carcinoma from secondary malignancies of liver. Indian J Pathol Microbiol 2018, 61, 510-515, doi:10.4103/ijpm.ijpm_788_16.

69. Hall, A.M.; Vilasi, A.; Garcia-Perez, I.; Lapsley, M.; Alston, C.L.; Pitceathly, R.D.; McFarland, R.; Schaefer, A.M.; Turnbull, D.M.; Beaumont, N.J., et al. The urinary proteome and metabonome differ from normal in adults with mitochondrial disease. Kidney Int 2015, 87, 610-622, doi:10.1038/ki.2014.297.

70. Welker, M.W.; Reichert, D.; Susser, S.; Sarrazin, C.; Martinez, Y.; Herrmann, E.; Zeuzem, S.; Piiper, A.; Kronenberger, B. Soluble serum CD81 is elevated in patients with chronic hepatitis C and correlates with alanine aminotransferase serum activity. PLoS One 2012, 7, e30796, doi:10.1371/journal.pone.0030796. 
71. Inoue, G.; Horiike, N.; Onji, M. The CD81 expression in liver in hepatocellular carcinoma. Int J Mol Med 2001, 7, 67-71, doi:10.3892/ijmm.7.1.67.

72. Mazzocca, A.; Liotta, F.; Carloni, V. Tetraspanin CD81-regulated cell motility plays a critical role in intrahepatic metastasis of hepatocellular carcinoma. Gastroenterology 2008, 135, 244-256.e241, doi:10.1053/j.gastro.2008.03.024.

73. Oguri, Y.; Shinoda, K.; Kim, H.; Alba, D.L.; Bolus, W.R.; Wang, Q.; Brown, Z.; Pradhan, R.N.; Tajima, K.; Yoneshiro, T., et al. CD81 Controls Beige Fat Progenitor Cell Growth and Energy Balance via FAK Signaling. Cell 2020, 182, 563-577.e520, doi:10.1016/j.cell.2020.06.021.

74. Simões, E.S.A.C.; Miranda, A.S.; Rocha, N.P.; Teixeira, A.L. Renin angiotensin system in liver diseases: Friend or foe? World J Gastroenterol 2017, 23, 3396-3406, doi:10.3748/wjg.v23.i19.3396.

75. Sansoè, G.; Aragno, M.; Wong, F. Pathways of hepatic and renal damage through non-classical activation of the renin-angiotensin system in chronic liver disease. Liver Int 2020, 40, 18-31, doi:10.1111/liv.14272.

76. Boettler, T.; Marjot, T.; Newsome, P.N.; Mondelli, M.U.; Maticic, M.; Cordero, E.; Jalan, R.; Moreau, R.; Cornberg, M.; Berg, T. Impact of COVID-19 on the care of patients with liver disease: EASL-ESCMID position paper after 6 months of the pandemic. JHEP Rep 2020, 2, 100169, doi:10.1016/j.jhepr.2020.100169.

77. Konturek, P.C.; Harsch, I.A.; Neurath, M.F.; Zopf, Y. COVID-19 - more than respiratory disease: a gastroenterologist's perspective. J Physiol Pharmacol 2020, 71, doi:10.26402/jpp.2020.2.02.

78. Fondevila, M.F.; Mercado-Gómez, M.; Rodríguez, A.; Gonzalez-Rellan, M.J.; Iruzubieta, P.; Valentí, V.; Escalada, J.; Schwaninger, M.; Prevot, V.; Dieguez, C., et al. Obese patients with NASH have increased hepatic expression of SARS-CoV-2 critical entry points. J Hepatol 2020, doi:10.1016/j.jhep.2020.09.027.

79. Zhang, C.; Wang, J.; Ma, X.; Wang, W.; Zhao, B.; Chen, Y.; Chen, C.; Bihl, J.C. ACE2-EPC-EXs protect ageing ECs against hypoxia/reoxygenation-induced injury through the miR-18a/Nox2/ROS pathway. $J$ Cell Mol Med 2018, 22, 1873-1882, doi:10.1111/jcmm.13471.

80. Wang, J.; Chen, S.; Bihl, J. Exosome-Mediated Transfer of ACE2 (Angiotensin-Converting Enzyme 2) from Endothelial Progenitor Cells Promotes Survival and Function of Endothelial Cell. Oxid Med Cell Longev 2020, 2020, 4213541, doi:10.1155/2020/4213541.

81. Hassanpour, M.; Rezaie, J.; Nouri, M.; Panahi, Y. The role of extracellular vesicles in COVID-19 virus infection. Infect Genet Evol 2020, 85, 104422, doi:10.1016/j.meegid.2020.104422.

82. Lambert, D.W.; Clarke, N.E.; Turner, A.J. Not just angiotensinases: new roles for the angiotensinconverting enzymes. Cell Mol Life Sci 2010, 67, 89-98, doi:10.1007/s00018-009-0152-x.

83. Park, J.; Jeong, D.; Chung, Y.W.; Kim, D.H.; Cheon, J.H.; Ryu, J.H. Quantitative Proteomic Analysis of the Expression of SARS-CoV-2 Receptors in the Gut of Patients with Chronic Enterocolitis. Yonsei Med J 2020, 61, 891-894, doi:10.3349/ymj.2020.61.10.891.

84. Zhao, Y.; Wu, H.; Xing, X.; Ma, Y.; Ji, S.; Xu, X.; Zhao, X.; Wang, S.; Jiang, W.; Fang, C., et al. CD13 Induces Autophagy to Promote Hepatocellular Carcinoma Cell Chemoresistance Through the P38/Hsp27/CREB/ATG7 Pathway. J Pharmacol Exp Ther 2020, 374, 512-520, doi:10.1124/jpet.120.265637.

85. Inal, J.M. Decoy ACE2-expressing extracellular vesicles that competitively bind SARS-CoV-2 as a possible COVID-19 therapy. Clin Sci (Lond) 2020, 134, 1301-1304, doi:10.1042/cs20200623.

86. Alukal, J.J.; John, S.; Thuluvath, P.J. Hyponatremia in Cirrhosis: An Update. Am J Gastroenterol 2020, 115, 1775-1785, doi:10.14309/ajg.0000000000000786. 
87. Dixon, S.J.; Lemberg, K.M.; Lamprecht, M.R.; Skouta, R.; Zaitsev, E.M.; Gleason, C.E.; Patel, D.N.; Bauer, A.J.; Cantley, A.M.; Yang, W.S., et al. Ferroptosis: an iron-dependent form of nonapoptotic cell death. Cell 2012, 149, 1060-1072, doi:10.1016/j.cell.2012.03.042.

88. Mao, L.; Zhao, T.; Song, Y.; Lin, L.; Fan, X.; Cui, B.; Feng, H.; Wang, X.; Yu, Q.; Zhang, J., et al. The emerging role of ferroptosis in non-cancer liver diseases: hype or increasing hope? Cell Death Dis 2020, 11, 518, doi:10.1038/s41419-020-2732-5.

89. Capelletti, M.M.; Manceau, H.; Puy, H.; Peoc'h, K. Ferroptosis in Liver Diseases: An Overview. Int J Mol Sci 2020, 21, doi:10.3390/ijms21144908.

90. Bebber, C.M.; Müller, F.; Prieto Clemente, L.; Weber, J.; von Karstedt, S. Ferroptosis in Cancer Cell Biology. Cancers (Basel) 2020, 12, doi:10.3390/cancers12010164.

91. Wang, W.; Lu, H.; Lu, X.; Wang, D.; Wang, Z.; Dai, W.; Wang, J.; Liu, P. Effect of tumor necrosis factor$\alpha$ on the expression of the ammonia transporter Rhcg in the brain in mice with acute liver failure. $J$ Neuroinflammation 2018, 15, 234, doi:10.1186/s12974-018-1264-8.

92. Aldridge, D.R.; Tranah, E.J.; Shawcross, D.L. Pathogenesis of hepatic encephalopathy: role of ammonia and systemic inflammation. J Clin Exp Hepatol 2015, 5, S7-s20, doi:10.1016/j.jceh.2014.06.004.

93. Kaffe, E.; Magkrioti, C.; Aidinis, V. Deregulated Lysophosphatidic Acid Metabolism and Signaling in Liver Cancer. Cancers (Basel) 2019, 11, doi:10.3390/cancers11111626.

94. Yoo, H.J.; Jung, K.J.; Kim, M.; Kang, M.; Jee, S.H.; Choi, Y.; Lee, J.H. Liver Cirrhosis Patients Who Had Normal Liver Function Before Liver Cirrhosis Development Have the Altered Metabolic Profiles Before the Disease Occurrence Compared to Healthy Controls. Front Physiol 2019, 10, 1421, doi:10.3389/fphys.2019.01421.

95. Key, C.C.; Bishop, A.C.; Wang, X.; Zhao, Q.; Chen, G.Y.; Quinn, M.A.; Zhu, X.; Zhang, Q.; Parks, J.S. Human GDPD3 overexpression promotes liver steatosis by increasing lysophosphatidic acid production and fatty acid uptake. J Lipid Res 2020, 61, 1075-1086, doi:10.1194/jlr.RA120000760.

96. Nakagawa, H.; Hikiba, Y.; Hirata, Y.; Font-Burgada, J.; Sakamoto, K.; Hayakawa, Y.; Taniguchi, K.; Umemura, A.; Kinoshita, H.; Sakitani, K., et al. Loss of liver E-cadherin induces sclerosing cholangitis and promotes carcinogenesis. Proc Natl Acad Sci $U$ S A 2014, 111, 1090-1095, doi:10.1073/pnas.1322731111.

97. Mirea, A.M.; Tack, C.J.; Chavakis, T.; Joosten, L.A.B.; Toonen, E.J.M. IL-1 Family Cytokine Pathways Underlying NAFLD: Towards New Treatment Strategies. Trends Mol Med 2018, 24, 458-471, doi:10.1016/j.molmed.2018.03.005.

98. Qin, Z.; Xiang, C.; Zhong, F.; Liu, Y.; Dong, Q.; Li, K.; Shi, W.; Ding, C.; Qin, L.; He, F. Transketolase (TKT) activity and nuclear localization promote hepatocellular carcinoma in a metabolic and a nonmetabolic manner. J Exp Clin Cancer Res 2019, 38, 154, doi:10.1186/s13046-019-1131-1.

99. Huang, A.; Dong, J.; Li, S.; Wang, C.; Ding, H.; Li, H.; Su, X.; Ge, X.; Sun, L.; Bai, C., et al. Exosomal transfer of vasorin expressed in hepatocellular carcinoma cells promotes migration of human umbilical vein endothelial cells. Int J Biol Sci 2015, 11, 961-969, doi:10.7150/ijbs.11943.

100. Bruno, S.; Pasquino, C.; Herrera Sanchez, M.B.; Tapparo, M.; Figliolini, F.; Grange, C.; Chiabotto, G.; Cedrino, M.; Deregibus, M.C.; Tetta, C., et al. HLSC-Derived Extracellular Vesicles Attenuate Liver Fibrosis and Inflammation in a Murine Model of Non-alcoholic Steatohepatitis. Mol Ther 2020, 28, 479489, doi:10.1016/j.ymthe.2019.10.016.

101. Yoo, W.; Lee, J.; Noh, K.H.; Lee, S.; Jung, D.; Kabir, M.H.; Park, D.; Lee, C.; Kwon, K.S.; Kim, J.S., et al. Progranulin attenuates liver fibrosis by downregulating the inflammatory response. Cell Death Dis 2019, 10, 758, doi:10.1038/s41419-019-1994-2. 
102. Jia, D.; Wang, Y.Y.; Wang, P.; Huang, Y.; Liang, D.Y.; Wang, D.; Cheng, C.; Zhang, C.; Guo, L.; Liang, P., et al. SVIP alleviates $\mathrm{CCl}(4)$-induced liver fibrosis via activating autophagy and protecting hepatocytes. Cell Death Dis 2019, 10, 71, doi:10.1038/s41419-019-1311-0.

103. Wiemann, S.U.; Satyanarayana, A.; Tsahuridu, M.; Tillmann, H.L.; Zender, L.; Klempnauer, J.; Flemming, P.; Franco, S.; Blasco, M.A.; Manns, M.P., et al. Hepatocyte telomere shortening and senescence are general markers of human liver cirrhosis. Faseb j 2002, 16, 935-942, doi:10.1096/fj.010977com.

104. Wang, Z.; Lin, H.; Hua, F.; Hu, Z.W. Repairing DNA damage by XRCC6/KU70 reverses TLR4deficiency-worsened HCC development via restoring senescence and autophagic flux. Autophagy 2013, 9, 925-927, doi:10.4161/auto.24229.

105. Magdaleno, F.; Arriazu, E.; Ruiz de Galarreta, M.; Chen, Y.; Ge, X.; Conde de la Rosa, L.; Nieto, N. Cartilage oligomeric matrix protein participates in the pathogenesis of liver fibrosis. J Hepatol 2016, 65, 963-971, doi:10.1016/j.jhep.2016.06.003.

106. Arora, V.; Baweja, S.; Sarin, S.K. Letter to the Editors: Relevance of Circulating Extracellular Vesicles Carrying Sphingolipid Cargo in Alcoholic Hepatitis: Need for more validation ! Hepatology 2020, doi:10.1002/hep.31465.

107. Rahman, M.A.; Patters, B.J.; Kodidela, S.; Kumar, S. Extracellular Vesicles: Intercellular Mediators in Alcohol-Induced Pathologies. J Neuroimmune Pharmacol 2020, 15, 409-421, doi:10.1007/s11481-01909848-z.

108. Hira, E.; Ono, T.; Dhar, D.K.; El-Assal, O.N.; Hishikawa, Y.; Yamanoi, A.; Nagasue, N. Overexpression of macrophage migration inhibitory factor induces angiogenesis and deteriorates prognosis after radical resection for hepatocellular carcinoma. Cancer 2005, 103, 588-598, doi:10.1002/cncr.20818.

109. Marin, V.; Poulsen, K.; Odena, G.; McMullen, M.R.; Altamirano, J.; Sancho-Bru, P.; Tiribelli, C.; Caballeria, J.; Rosso, N.; Bataller, R., et al. Hepatocyte-derived macrophage migration inhibitory factor mediates alcohol-induced liver injury in mice and patients. J Hepatol 2017, 67, 1018-1025, doi:10.1016/j.jhep.2017.06.014.

110. Poulsen, K.L.; McMullen, M.R.; Huang, E.; Kibler, C.D.; Sheehan, M.M.; Leng, L.; Bucala, R.; Nagy, L.E. Novel Role of Macrophage Migration Inhibitory Factor in Upstream Control of the Unfolded Protein Response After Ethanol Feeding in Mice. Alcohol Clin Exp Res 2019, 43, 1439-1451, doi:10.1111/acer.14065.

111. Costa-Silva, B.; Aiello, N.M.; Ocean, A.J.; Singh, S.; Zhang, H.; Thakur, B.K.; Becker, A.; Hoshino, A.; Mark, M.T.; Molina, H., et al. Pancreatic cancer exosomes initiate pre-metastatic niche formation in the liver. Nat Cell Biol 2015, 17, 816-826, doi:10.1038/ncb3169.

112. Wiśniewski, J.R.; Zougman, A.; Nagaraj, N.; Mann, M. Universal sample preparation method for proteome analysis. Nat Methods 2009, 6, 359-362, doi:10.1038/nmeth.1322.

113. Tyanova, S.; Temu, T.; Sinitcyn, P.; Carlson, A.; Hein, M.Y.; Geiger, T.; Mann, M.; Cox, J. The Perseus computational platform for comprehensive analysis of (prote)omics data. Nat Methods 2016, 13, 731-740, doi:10.1038/nmeth.3901.

114. Huang da, W.; Sherman, B.T.; Lempicki, R.A. Systematic and integrative analysis of large gene lists using DAVID bioinformatics resources. Nat Protoc 2009, 4, 44-57, doi:10.1038/nprot.2008.211.

115. Manna, S.K.; Thompson, M.D.; Gonzalez, F.J. Application of mass spectrometry-based metabolomics in identification of early noninvasive biomarkers of alcohol-induced liver disease using mouse model. Adv Exp Med Biol 2015, 815, 217-238, doi:10.1007/978-3-319-09614-8_13. 
116. Zehra, M.; Curry, J.C.; Pillai, S.S.; Lakhani, H.V.; Edwards, C.E.; Sodhi, K. Elucidating Potential Profibrotic Mechanisms of Emerging Biomarkers for Early Prognosis of Hepatic Fibrosis. Int J Mol Sci 2020, 21, doi:10.3390/ijms21134737.

117. Chen, Y.; Manna, S.K.; Golla, S.; Krausz, K.W.; Cai, Y.; Garcia-Milian, R.; Chakraborty, T.; Chakraborty, J.; Chatterjee, R.; Thompson, D.C., et al. Glutathione deficiency-elicited reprogramming of hepatic metabolism protects against alcohol-induced steatosis. Free Radic Biol Med 2019, 143, 127-139, doi:10.1016/j.freeradbiomed.2019.07.025.

118. Bala, S.; Petrasek, J.; Mundkur, S.; Catalano, D.; Levin, I.; Ward, J.; Alao, H.; Kodys, K.; Szabo, G. Circulating microRNAs in exosomes indicate hepatocyte injury and inflammation in alcoholic, druginduced, and inflammatory liver diseases. Hepatology 2012, 56, 1946-1957, doi:10.1002/hep.25873.

119. Sun, N.; Lee, Y.T.; Zhang, R.Y.; Kao, R.; Teng, P.C.; Yang, Y.; Yang, P.; Wang, J.J.; Smalley, M.; Chen, P.J., et al. Purification of HCC-specific extracellular vesicles on nanosubstrates for early HCC detection by digital scoring. Nat Commun 2020, 11, 4489, doi:10.1038/s41467-020-18311-0. 